\title{
In Silico Assessment of Efficacy and Safety of IKur Inhibitors in Chronic Atrial Fibrillation: Role of Kinetics and State-Dependence of Drug Binding
}

\author{
Nicholas Ellinwood ${ }^{1}$, Dobromir Dobrev ${ }^{2}$, Stefano Morotti ${ }^{1 *}$ and Eleonora Grandi ${ }^{1}$ \\ ${ }^{1}$ Department of Pharmacology, University of California, Davis, Davis, CA, United States, ${ }^{2}$ West German Heart and Vascular \\ Center, Institute of Pharmacology, University Duisburg-Essen, Essen, Germany
}

\section{OPEN ACCESS}

Edited by:

Domenico Tricarico,

Università degli studi di Bari Aldo

Moro, Italy

Reviewed by:

Adam Hill,

Victor Chang Cardiac Research

Institute, Australia

Clemens Möller,

Hochschule Albstadt-Sigmaringen,

Germany

*Correspondence:

Stefano Morott

smorotti@gmail.com

Specialty section:

This article was submitted to Pharmacology of lon Channels and

Channelopathies,

a section of the journal

Frontiers in Pharmacology

Received: 07 August 2017

Accepted: 23 October 2017

Published: 07 November 2017

Citation:

Ellinwood N, Dobrev D, Morotti S and Grandi E (2017) In Silico Assessment of Efficacy and Safety of I Kur Inhibitors in Chronic Atrial Fibrillation: Role of Kinetics and State-Dependence of

Drug Binding.

Front. Pharmacol. 8:799

doi: 10.3389/fphar.2017.00799
Current pharmacological therapy against atrial fibrillation (AF), the most common cardiac arrhythmia, is limited by moderate efficacy and adverse side effects including ventricular proarrhythmia and organ toxicity. One way to circumvent the former is to target ion channels that are predominantly expressed in atria vs. ventricles, such as $K_{V} 1.5$, carrying the ultra-rapid delayed-rectifier $\mathrm{K}^{+}$current $\left(\mathrm{I}_{\mathrm{Kur}}\right)$. Recently, we used an in silico strategy to define optimal $K_{V} 1.5$-targeting drug characteristics, including kinetics and state-dependent binding, that maximize AF-selectivity in human atrial cardiomyocytes in normal sinus rhythm (nSR). However, because of evidence for $I_{\text {Kur }}$ being strongly diminished in long-standing persistent (chronic) AF (cAF), the therapeutic potential of drugs targeting $I_{\text {Kur }}$ may be limited in CAF patients. Here, we sought to simulate the efficacy (and safety) of I Kur inhibitors in CAF conditions. To this end, we utilized sensitivity analysis of our human atrial cardiomyocyte model to assess the importance of $I_{\text {Kur }}$ for atrial cardiomyocyte electrophysiological properties, simulated hundreds of theoretical drugs to reveal those exhibiting anti-AF selectivity, and compared the results obtained in $\mathrm{CAF}$ with those in nSR. We found that despite being downregulated, IKur contributes more prominently to action potential (AP) and effective refractory period (ERP) duration in cAF vs. nSR, with ideal drugs improving atrial electrophysiology (e.g., ERP prolongation) more in CAF than in nSR. Notably, the trajectory of the AP during CAF is such that more $I_{\text {Kur }}$ is available during the more depolarized plateau potential. Furthermore, IKur block in CAF has less cardiotoxic effects (e.g., AP duration not exceeding nSR values) and can increase $\mathrm{Ca}^{2+}$ transient amplitude thereby enhancing atrial contractility. We propose that in silico strategies such as that presented here should be combined with in vitro and in vivo assays to validate model predictions and facilitate the ongoing search for novel agents against $A F$.

Keywords: ultra-rapid delayed-rectifier $\mathrm{K}^{+}$current, atrial fibrillation, mathematical modeling, ion channel blockers

Abbreviations: AP, action potential; $\mathrm{APD}$, AP duration; $\mathrm{APD}_{40}$, $\mathrm{APD}$ to $40 \%$ repolarization; $\mathrm{APD}_{90}$, $\mathrm{APD}$ to $90 \%$ repolarization; $\mathrm{AF}$, atrial fibrillation; $\mathrm{C}$, closed state; $\mathrm{cAF}$, chronic $\mathrm{AF} ; \mathrm{CaT}^{\mathrm{C}} \mathrm{Ca}^{2+}$ transient; $\mathrm{CaT}_{\mathrm{amp}}$, $\mathrm{CaT}$ amplitude; $\mathrm{CL}$, cycle length; EAD, early afterdepolarization; $\mathrm{E}_{\mathrm{m}}$, membrane potential; ERP, effective refractory period; $\mathrm{G}_{\mathrm{Kur}}$, maximal conductance of the ultra-rapid delayed-rectifier $\mathrm{K}^{+}$current; I, inactivated state; $\mathrm{I}_{\mathrm{Kur}}$, ultra-rapid delayed-rectifier $\mathrm{K}^{+}$current; $\mathrm{nSR}$, normal sinus rhythm; $\mathrm{O}$, open state. 


\section{INTRODUCTION}

Atrial fibrillation (AF) is characterized by rapid, irregular heart contractions following fast, disorganized electrical signals in the atria. AF is the most common cardiac arrhythmia, occurring in $1-2 \%$ of the general population and projected to increase dramatically in the coming decades (to $4 \%$ by 2050 ) with an aging westernized population (Andrade et al., 2014). The most effective current treatment for preventing recurrence of $\mathrm{AF}$ in the clinic is radiofrequency ablation. Pharmacological therapy against AF is limited by low efficacy and substantial adverse side effects including an increased risk of lethal ventricular tachyarrhythmias.

To maximize efficacy and minimize proarrhythmic risk, an AF-selective drug should exert potent effects on fibrillating atria without significantly impacting ventricular tissue function during normal sinus rhythm (nSR) (Ehrlich et al., 2008; Van Wagoner et al., 2015). A potential strategy to achieve this goal is to target ion channels that are predominantly expressed in atria vs. ventricles, such as $\mathrm{K}_{\mathrm{V}} 1.5$, carrying the ultra-rapid delayedrectifier $\mathrm{K}^{+}$current ( $\mathrm{I}_{\mathrm{Kur}}$ ). Genetic mutations causing both lossand gain-of-function of $\mathrm{I}_{\mathrm{Kur}}$ have been associated with atrial arrhythmias in human (Olson et al., 2006; Christophersen et al., 2013; Colman et al., 2017). In a previous investigation, we used an in silico strategy to define optimal $\mathrm{K}_{\mathrm{V}} 1.5$-targeting drug characteristics, including kinetics and state-dependent binding, that maximize AF-selectivity (i.e., fast pacing-rate selectivity) in human atrial cardiomyocytes (Ellinwood et al., 2017). Because this work was conducted in atrial cardiomyocytes under nSR conditions, the best-performing drug properties identified would have relevance for patients with paroxysmal AF that have not undergone extensive AF-related electrical remodeling (Grandi et al., 2012; Nattel and Dobrev, 2016).

Building on our previously established simulation framework, the major goal of this investigation was to determine the optimal drug characteristics of $\mathrm{I}_{\mathrm{Kur}}$ inhibitors in long-standing persistent (chronic) AF (cAF) conditions. Although not a universal finding (Yue et al., 1997; Bosch et al., 1999; Grammer et al., 2000; Workman et al., 2001), previous reports showed that $\mathrm{I}_{\mathrm{Kur}}$ is strongly diminished in cAF patients (Van Wagoner et al., 1997; Brandt et al., 2000; Van Wagoner and Nerbonne, 2000; Dobrev and Ravens, 2003; Christ et al., 2008; Caballero et al., 2010), making the therapeutic potential of inhibitors targeting this current uncertain (Ravens et al., 2013; Grandi and Maleckar, 2016). Indeed, evidence of anti-arrhythmic efficacy of $\mathrm{K}_{\mathrm{V}} 1.5$ inhibitors in clinical trials is lacking (Ravens et al., 2013). However, recent studies have suggested an anti-arrhythmic potential of $\mathrm{I}_{\mathrm{Kur}}$-targeting drugs in cAF (Christ et al., 2008; Ford et al., 2013, 2016; Loose et al., 2014), as they can prolong action potential (AP) and effective refractory period (ERP) in atrial cardiomyocytes of cAF patients. Moreover, experimental evidence suggests that block of $\mathrm{I}_{\mathrm{Kur}}$ enhances force of contraction of isolated human atrial trabeculae in cAF (Wettwer et al., 2004; Schotten et al., 2007). Our human atrial cardiomyocyte model confirmed that block of $\mathrm{I}_{\mathrm{Kur}}$ results in prolongation and elevation of the AP plateau, which augments the $\mathrm{Ca}^{2+}$ transient (CaT) amplitude $\left(\mathrm{CaT}_{\mathrm{amp}}\right)$, thereby eliciting a positive inotropic effect (Grandi et al., 2011). Thus, I Kur might be a useful atrialselective target to potentially prevent reentry and related atrial hypocontractility in CAF. We propose that our computational approach, combined with in vivo and in vitro validation, might be useful to facilitate the identification of atrial-selective antiarrhythmic drugs against AF (Bers and Grandi, 2011; Grandi and Maleckar, 2016).

\section{METHODS}

\section{Atrial AP Model and Simulations}

APs and CaTs were simulated with the Grandi et al. model of the human atrial cardiomyocyte in nSR and cAF (Grandi et al., 2011; Morotti et al., 2016b). I Kur gating was described by a 6-state Markov type model (Figure 1A) as in Ellinwood et al. (2017), and I Kur maximal conductance $\left(\mathrm{G}_{\mathrm{Kur}}\right)$ in cAF was reduced by $50 \%$ compared to nSR (Grandi et al., 2011).

Simulations were equilibrated for 300 beats at $1-\mathrm{Hz}$ pacing or 900 beats at $3-\mathrm{Hz}$ pacing. After the $300^{\text {th }}$ or $900^{\text {th }}$ beat, the time to 40 and $90 \%$ repolarization of the $\mathrm{AP}\left(\mathrm{APD}_{40}\right.$ and $\left.\mathrm{APD}_{90}\right)$ were calculated, along with diastolic intracellular $\mathrm{Ca}^{2+}$ concentration $\left(\left[\mathrm{Ca}^{2+}\right]_{\mathrm{i}}\right), \mathrm{CaT}_{\text {amp }}$ and time to $50 \% \mathrm{CaT}$ decay. The atrial ERP was determined using a standard $S_{1}-S_{2}$ premature stimulation protocol (Wang et al., 1996; Shinagawa et al., 2000; Christ et al., 2008; Zhao et al., 2009), where the $\mathrm{S}_{1}$ basal stimulus (5 $\mathrm{ms}$ in duration) was applied to a steadystate human atrial cardiomyocyte model. As previously described (Ellinwood et al., 2017), ERP was determined by applying the premature $S_{2}$ stimulus $(5 \mathrm{~ms}$ in duration, 2 -fold the diastolic threshold of excitation) at progressively smaller $S_{1}-S_{2}$ intervals from $700 \mathrm{~ms}$ to refractoriness by decrements of $2 \mathrm{~ms}$. The longest $\mathrm{S}_{1}-\mathrm{S}_{2}$ interval that failed to elicit an AP was taken as the local ERP (i.e., maximum upstroke velocity $\geq 5 \mathrm{~V} / \mathrm{s}$ and AP with an amplitude $\geq 50 \%$ of the amplitude of the preceding AP elicited by $S_{1}$ ).

An irregular pacing protocol was run for $20 \mathrm{~s}$, starting from steady-state conditions at the fixed $3-\mathrm{Hz}$ pacing. The cycle length (CL) was allowed to vary randomly following a uniform distribution between 285.7 and $400 \mathrm{~ms}$, corresponding to a minimum pacing frequency of $2.5 \mathrm{~Hz}$ and a maximum pacing frequency of $3.5 \mathrm{~Hz}$, with a mean of $333.3 \mathrm{~ms}$ (corresponding to 3$\mathrm{Hz}$ pacing). The time course of membrane potential $\left(\mathrm{E}_{\mathrm{m}}\right), \mathrm{APD}_{90}$, and CL was tracked over the course of the simulation.

All simulations and analysis were performed in MATLAB (The MathWorks, Natick, MA, USA) using the stiff ordinary differential equation solver ode15s. The model code is available for download at the following webpages: https://somapp.ucdmc. ucdavis.edu/Pharmacology/bers/ and http://elegrandi.wixsite. com/grandilab/downloads.

\section{Parameter Sensitivity Analysis}

Parameter sensitivity analysis was performed with the population-based approach described in Sobie (2009), Morotti et al. (2017), and Morotti and Grandi (2017) to investigate the role of various currents and transporters in the regulation of AP duration (APD), ERP, and CaT characteristics. Two populations of 900 atrial cardiomyocyte models were generated by randomly 


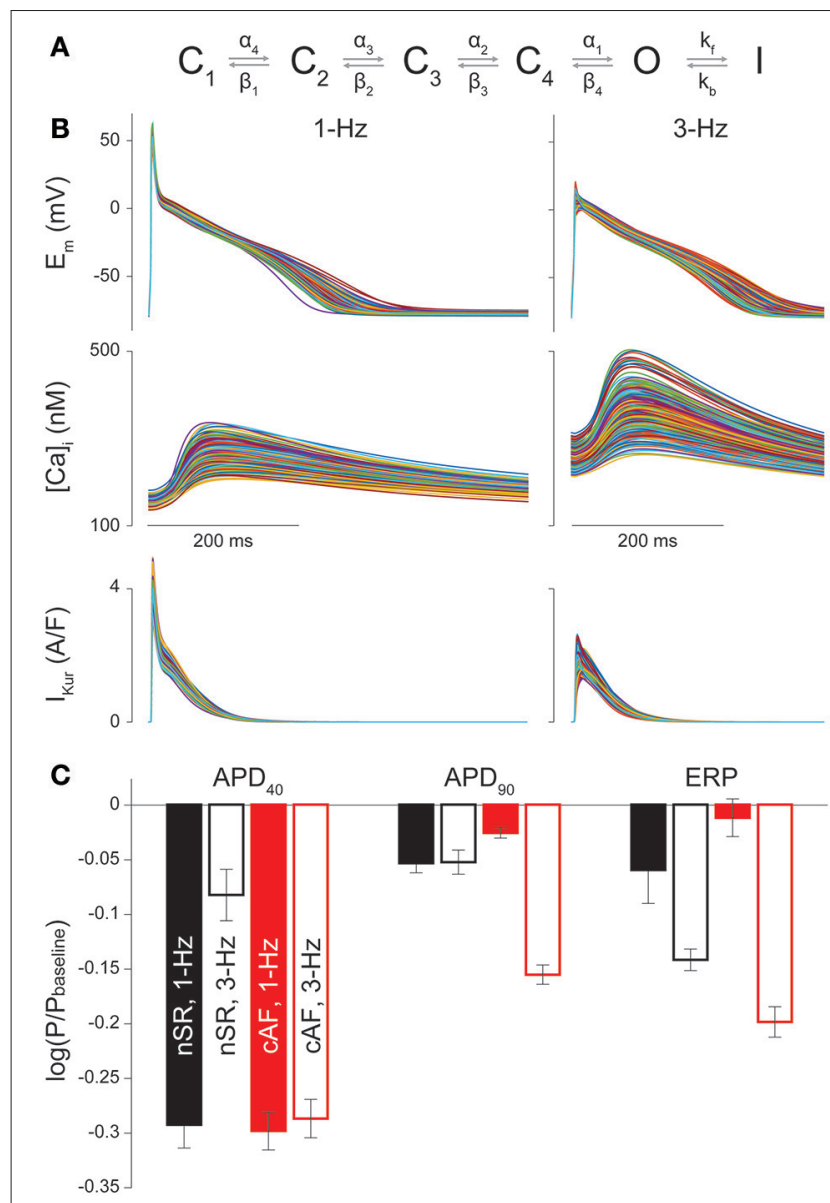

FIGURE 1 | Sensitivity of $n S R$ and cAF cardiomyocyte electrophysiology to $I_{\text {Kur }}$ changes. (A) Drug-free Markov model of $I_{K u r}$ derived from Zhou et al. (2012). The model has 4 closed states $\left(\mathrm{C}_{1}, \mathrm{C}_{2}, \mathrm{C}_{3}, \mathrm{C}_{4}\right)$, a conducting open state (O), and an inactivated state (I). Transition rates equations and parameters are those in Ellinwood et al. (2017). (B) AP, CaT, and $I_{K u r}$ in a subset of $300 \mathrm{cAF}$ cardiomyocyte model variants at $1-\mathrm{Hz}$ and $3-\mathrm{Hz}$ pacing rates. (C) Bar graphs show the average regression coefficients indicating how perturbations in $\mathrm{G}_{\mathrm{Kur}}$ affect $\mathrm{APD}_{40}, \mathrm{APD}_{90}$, and $\mathrm{ERP}$ in $\mathrm{nSR}$ and $\mathrm{cAF}$ at $1-\mathrm{Hz}$ and $3-\mathrm{Hz}$ pacing rates. Error bars represent one standard deviation.

varying the values of 18 parameters (see list in the Supplementary Materials) in the baseline nSR and cAF models. Specifically, the default value of each conductance or maximal transport rate was independently varied with a log-normal distribution (with standard deviation of 0.1 ). Multivariable regression (non-linear iterative partial least squares method) on log-transformed values was performed for 30 random subsets of 300 model variants from the 900-variant population to correlate the variation in each parameter to the consequent effect on each output. In Figure 1C and Figures S1-S6 bars represent the mean regression coefficients and error bars represent one standard deviation.

\section{Kv1.5 Drug-Binding Model}

We utilized our recent $\mathrm{I}_{\text {Kur }}$ Markov formulation and approach to describe various drug- $\mathrm{K}_{\mathrm{V}} 1.5$ channel binding schemes (Figures 2A,F; Ellinwood et al., 2017), as done by Lee et al.
(2016). We previously showed that open state (O) blockers and open and inactivated state $(\mathrm{O} \& \mathrm{I})$ blockers that target $\mathrm{K}_{\mathrm{V}} 1.5$ display fast pacing-rate selectivity (Ellinwood et al., 2017). Thus, we focused on these two types of inhibitors when examining the relationship between electrophysiological parameters and drugbinding kinetics in cAF. We considered different theoretical drugs with variable forward $\left(\mathrm{k}_{\mathrm{on}}\right)$ and reverse $\left(\mathrm{k}_{\mathrm{off}}\right)$ drugbinding rates to the open and inactivated states of the $\mathrm{K}_{\mathrm{V}} 1.5$ channel in the predicted physiological range of $0.01-100 \mathrm{~s}^{-1}$ (Lagrutta et al., 2006) using half-logarithmic increments resulting in nine transition rates for each drug state transition $(0.01,0.03$, $\left.0.1,0.3,1,3,10,30,100 \mathrm{~s}^{-1}\right)$. For a particular state of the channel, dissociation constants $\left(\mathrm{K}_{\mathrm{d}}\right)$ for our drug scenarios were calculated as $\mathrm{k}_{\mathrm{off}} / \mathrm{k}_{\mathrm{on}}$, and affinity constants were calculated as $\mathrm{k}_{\mathrm{on}} / \mathrm{k}_{\mathrm{off}}$. To investigate the effects of these drug characteristics, for a given state-dependent binding inhibitor, we varied $\mathrm{k}_{\mathrm{on}}$ and $\mathrm{k}_{\mathrm{off}}$ together $\left(\mathrm{k}_{\mathrm{on}}=\mathrm{k}_{\mathrm{off}}\right)$ or considered all permutations of the nine different rates of drug binding (producing a total of 81 different drug scenarios). For drugs that could bind to multiple states of the $K_{V} 1.5$ channel, we also varied the relative affinity to open $\left(\mathrm{K}_{\mathrm{O}}\right)$ vs. inactivated state $\left(\mathrm{K}_{\mathrm{I}}\right)$. For $\mathrm{O}$ \& I blockers, we included transitions between drug-bound states (orange transitions in Figure 2F) when specified. All drugs were simulated at the concentration causing a 50\% reduction in peak $\mathrm{I}_{\mathrm{Kur}}$ (i.e., $\mathrm{IC}_{50}$ ). $\mathrm{IC}_{50}$ values were computed as described previously (Ellinwood et al., 2017), using a 200-ms down-ramp voltage-clamp protocol from +30 to $-60 \mathrm{mV}$. After the application of a given [drug] (range: $1 \mathrm{nM}-1 \mathrm{M}$ ), we allowed sufficient time for the degree of block to reach equilibrium. $\mathrm{IC}_{50}$ values were calculated at 1 and $3-\mathrm{Hz}$ pacing rates as the [drug] causing a 50\% reduction in peak $\mathrm{I}_{\mathrm{Kur}}$ compared to drug-free conditions. We chose the down-ramp, as compared to a typical square pulse, because it more closely resembles the relative state occupancies of the closed states, open state, and inactivated state of the $\mathrm{K}_{\mathrm{V}} 1.5$ channel during a physiological atrial AP, as we have shown in (Ellinwood et al., 2017).

\section{RESULTS}

\section{Role of $\mathrm{I}_{\mathrm{Kur}}$ in nSR and cAF Atrial Electrophysiology}

We built 900 variations of our nSR and cAF human atrial cardiomyocyte models (Grandi et al., 2011) at 1- and 3$\mathrm{Hz}$ pacing, and performed parameter sensitivity analysis on 30 random subsets of 300 model variants to determine how alterations in each maximum ionic conductance/transport rate differentially (in cAF vs. nSR) affect electrophysiological properties including $\mathrm{APD}_{40}, \mathrm{APD}_{90}, \mathrm{ERP}, \mathrm{CaT}_{\mathrm{amp}}$, diastolic $\left[\mathrm{Ca}^{2+}\right]_{\mathrm{i}}$, and time to $50 \%$ CaT decay (Figures S1-S6). Simulated APs and CaTs in a representative group of $300 \mathrm{cAF}$ cardiomyocyte model variants are shown in Figure 1B, and the average regression coefficients for $\mathrm{G}_{\mathrm{Kur}}$ in $\mathrm{nSR}$ and $\mathrm{cAF}$ conditions at 1 - and $3-\mathrm{Hz}$ pacing are in Figure 1C. The values are negative because an increase in $\mathrm{I}_{\text {Kur }}$ shortens $\mathrm{APD}_{40}, \mathrm{APD}_{90}$, and ERP on average according to the regression algorithm. The analysis revealed that, while at a slow pacing rate $\mathrm{APD}_{90}$ and $\mathrm{ERP}$ 
A

$$
\mathrm{C}_{1} \rightleftharpoons \mathrm{C}_{2} \rightleftharpoons \mathrm{C}_{3} \rightleftharpoons \mathrm{C}_{4} \rightleftharpoons \underset{\substack{\mathrm{on}_{\mathrm{on}} \| \mathrm{k}_{\text {off }} \\ \mathrm{Od}}}{\mathrm{O}} \rightleftharpoons \mathrm{I}
$$

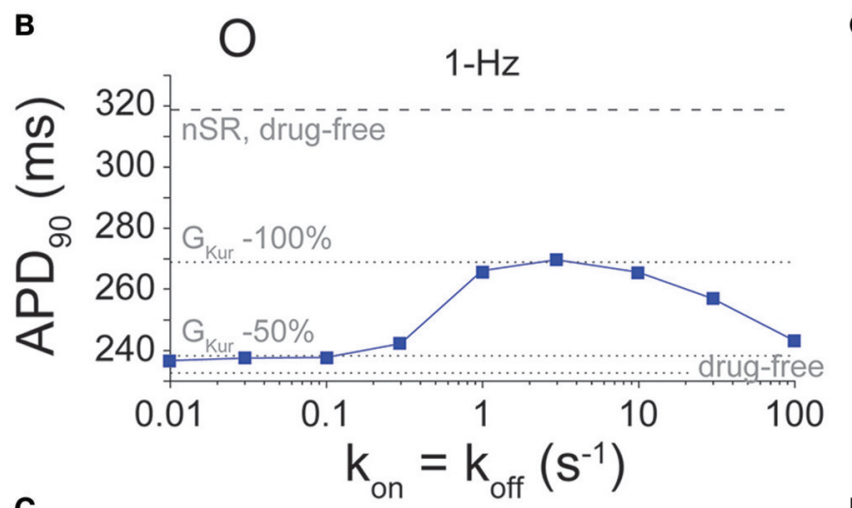

C

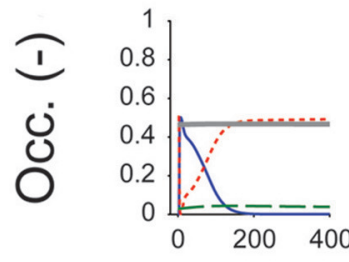

D

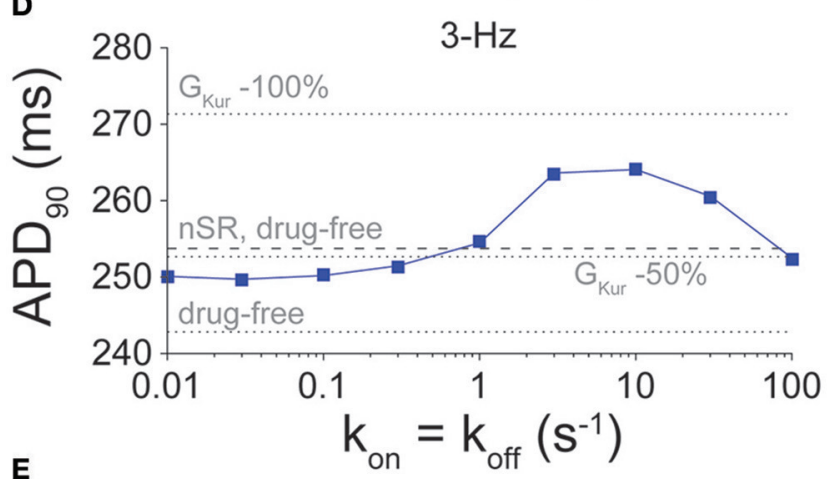

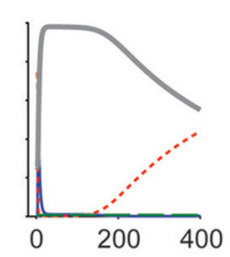

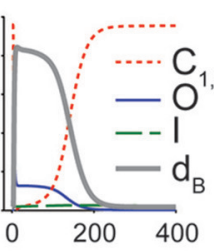

Time (ms)

$3-\mathrm{Hz}$

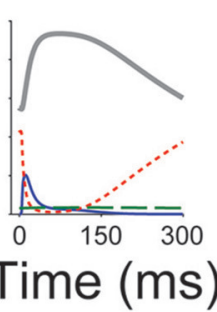

$\mathbf{F}$

$$
\begin{aligned}
& \mathrm{C}_{1} \rightleftharpoons \mathrm{C}_{2} \rightleftharpoons \mathrm{C}_{3} \rightleftharpoons \mathrm{C}_{4} \rightleftharpoons \mathrm{O} \underset{\mathrm{k}_{\mathrm{b}}}{\stackrel{\mathrm{k}_{\mathrm{f}}}{\rightleftarrows}} \mathrm{I} \\
& k_{\text {on }}\left\|k_{\text {off }} \quad k_{\text {on }}\right\| k_{\text {off }} \\
& \text { Od } \underset{k_{b}}{\stackrel{k_{t}}{\rightleftarrows}} \text { Id }
\end{aligned}
$$

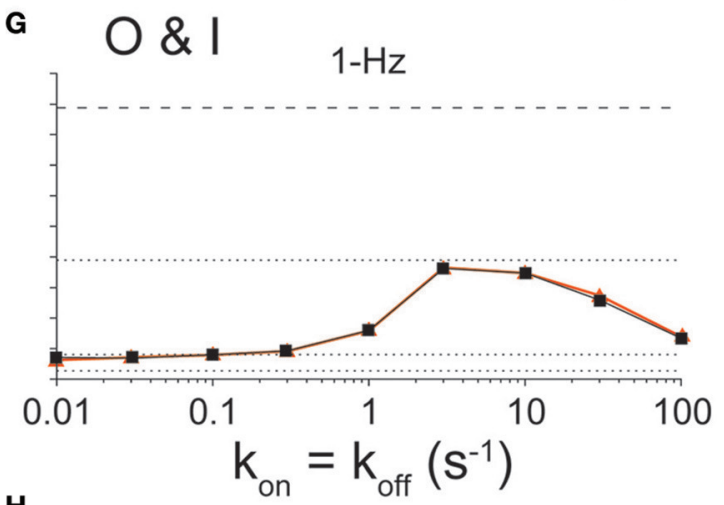

H

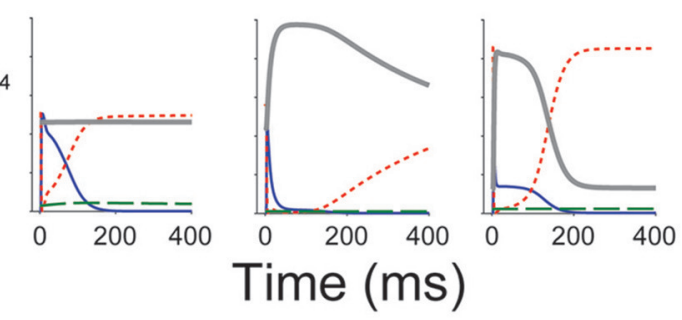

I
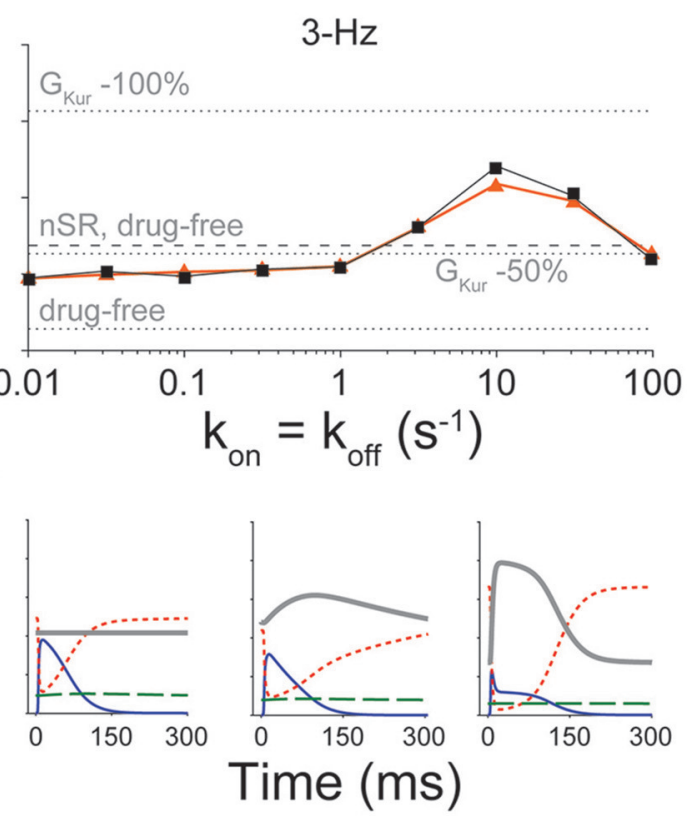

FIGURE 2 | Effect of state-dependence and kinetics of drug binding on APD90. APDgo was determined for open (schematic in A, B, 1-Hz and $\mathbf{D}, 3-\mathrm{Hz}$ pacing rate) and open and inactivated (schematic in $\mathbf{F}, \mathbf{G} 1-\mathrm{Hz}$ and $\mathbf{I}, 3-\mathrm{Hz}$ pacing rate) state blockers given nine different rates of binding kinetics between 0.01 and $100 \mathrm{~s}^{-1}$ using half-logarithmic increments, whereby $\mathrm{k}_{\text {off }}=\mathrm{k}_{\mathrm{on}}, \mathrm{K}_{\mathrm{d}}=1 \mu \mathrm{M}$. For $\mathrm{O}$ \& I blockers, we either allowed or prevented transitions between drug-bound states (orange vs. black traces in G,I). Simulations were also run in nSR and cAF drug-free conditions, and in cAF given a 50 and $100 \%$ reduction in $\mathrm{G}_{\mathrm{Kur}}$ (dotted and dashed lines in $\mathbf{B}, \mathbf{D}, \mathbf{G}, \mathbf{I})$. Simulations were equilibrated for 300 beats at $1-\mathrm{Hz}$ pacing or 900 beats at $3-\mathrm{Hz}$ pacing using a [drug] equal to the $\mathrm{IC}_{50}$ value. (C,E, $\left.\mathbf{H}, \mathbf{J}\right)$ show the closed, open, inactivated and drug-bound $\left(d_{B}\right.$, i.e., Od or Od+ld ) state occupancies during an AP for three different drug-binding kinetics $\left(k_{\text {off }}=k_{o n}=0.01,3\right.$, and $\left.100 \mathrm{~s}^{-1}\right)$. 
are more sensitive to changes in $\mathrm{G}_{\mathrm{Kur}}, \mathrm{APD}_{40}$ is similarly sensitive in $\mathrm{nSR}$ and cAF (Figure 1C). At $3-\mathrm{Hz}$ pacing, $\mathrm{G}_{\text {Kur }}$ impacts AP and ERP prolongation more in CAF vs. nSR despite the fact that $\mathrm{G}_{\mathrm{Kur}}$ is smaller in cAF conditions. This points to $\mathrm{I}_{\text {Kur }}$ inhibition as a promising approach to counteract the abbreviated APD and ERP in CAF, while having a more moderate effect at physiological pacing rates. Therefore, we next ran simulations to reveal $\mathrm{I}_{\text {Kur- }}$ targeting drug properties that exhibit anti-AF selectivity and efficacy along with minimized proarrhythmic risk in CAF.

\section{Effect of Conformational State Specificity and Binding/Unbinding Kinetics on Human Atrial Cardiomyocyte APD at Normal and Fast Pacing Rates in CAF Conditions}

Figure 2 shows changes in APD caused by $\mathrm{O}$ and $\mathrm{O} \& \mathrm{I}$ inhibitors at varying drug-binding kinetics, whereby $\mathrm{k}_{\mathrm{on}}$ is set equal to $\mathrm{k}_{\mathrm{off}}$ (i.e., $\mathrm{K}_{\mathrm{d}}=1 \mu \mathrm{M}$ ). These are compared to no block, 50, and $100 \%$ reduction in $\mathrm{G}_{\mathrm{Kur}}$ in cAF conditions, as well as no block in nSR conditions. Similar to our findings in nSR (Ellinwood et al., 2017), both types of inhibitors display a biphasic relationship between APD and drug-binding kinetics at $1-$ and $3-\mathrm{Hz}$ pacing. At $1-\mathrm{Hz}$ pacing, APD in the presence of drug is comparable to a $50 \%$ reduction in $\mathrm{G}_{\mathrm{Kur}}$ at slow and fast drug-binding kinetics (Figures 2B,G). Significant APD prolongation is only seen for intermediate drug-binding kinetics $\left(0.3-30 \mathrm{~s}^{-1}\right.$ for the open state blocker and $1-30 \mathrm{~s}^{-1}$ for the open and inactivated state blocker), and goes well beyond the little APD prolongation resulting from a constant $50 \%$ reduction in $\mathrm{G}_{\mathrm{Kur}}$. However, even the maximal APD prolongation produced by an $\mathrm{O}$ or $\mathrm{O} \& \mathrm{I}$ inhibitor in $\mathrm{CAF}$ is still $\sim 50 \mathrm{~ms}$ less than the APD in nSR in drug-free conditions, which we interpret to suggest that such drugs would have limited toxicity at $1-\mathrm{Hz}$ pacing rate.

At $3-\mathrm{Hz}$ pacing, the two types of inhibitors cause stronger relative prolongation as compared to $1-\mathrm{Hz}$ pacing across the same range of drug-binding kinetics (Figures 2D,I). Notably, all simulated drugs caused APD prolongation at $3-\mathrm{Hz}$ pacing, but the maximal prolongation produced by these theoretical inhibitors did not match the APD prolongation caused by a $100 \%$ reduction in $\mathrm{G}_{\mathrm{Kur}}$. However, drugs with intermediate drugbinding kinetics (3-30 $s^{-1}$ for the O blocker and 10-30 $s^{-1}$ for the $\mathrm{O} \& \mathrm{I}$ blocker) did extend the APD at $3-\mathrm{Hz}$ pacing above the APD in nSR conditions given no block of $\mathrm{I}_{\text {Kur. Thus, even }}$ though $\mathrm{G}_{\mathrm{Kur}}$ is reduced by $50 \%$ in $\mathrm{cAF}$ as compared to $\mathrm{nSR}$, Figure 2 illustrates that $\mathrm{I}_{\text {Kur }}$ inhibitors can still prolong APD in cAF, particularly at $3-\mathrm{Hz}$ pacing.

Figures 2C,H,E,J display the closed (red), open (blue), inactivated (green), and drug-bound (gray) state occupancies during the steady-state AP for the slowest $\left(0.01 \mathrm{~s}^{-1}\right)$, intermediate $\left(3 \mathrm{~s}^{-1}\right)$, and fastest $\left(100 \mathrm{~s}^{-1}\right)$ drug-binding rates. In general, for the slowest drug-binding kinetics, the inhibitors do not bind readily during the AP, and the drug-bound state stays level below 0.4. At intermediate drug-binding kinetics, the inhibitors bind readily during the AP, thus significantly shrinking the open state occupancy. In addition, the off-rate of drug binding is slow enough to achieve maintenance in the drug-bound state during the AP. This allows for considerable
AP prolongation, almost mimicking complete block of $\mathrm{I}_{\mathrm{Kur}}$. Finally, for the fastest drug-binding kinetics, the drugs again bind readily during the AP, but the off-rate of drug binding is so fast as to cause cycling between the drug-free open state and the drug-bound open state during a single AP. This results in prolongation of the drug-free open state occupancy later in the AP that limits AP prolongation. These results are consistent with our previous simulations in nSR. However, given the more positive plateau in the $\mathrm{CAF}$ cardiomyocyte $\mathrm{AP}, \mathrm{K}_{\mathrm{V}} 1.5$ channels stay open longer, and inactivate more markedly (especially at $3-\mathrm{Hz}$ pacing) as compared to nSR (Figure S7).

Given not only the rapid, but irregular electrical activity seen with AF, we sought to determine how the kinetics of drug binding of $\mathrm{I}_{\mathrm{Kur}}$ inhibitors affected the time course of $\mathrm{E}_{\mathrm{m}}$ (Figure 3B) and $\mathrm{APD}_{90}$ (Figure 3C) in cAF cardiomyocytes with a randomly variable CL (Figure 3A). Results in drug-free conditions and for an $\mathrm{O} \& \mathrm{I}$ blocker (modeled as in Figure 2F, black) with $\mathrm{k}_{\mathrm{on}}$ $=\mathrm{k}_{\mathrm{off}}\left(\mathrm{K}_{\mathrm{d}}=1 \mu \mathrm{M}\right)$ in Figure 3 again demonstrate a biphasic relationship between drug-binding kinetics and average $\mathrm{APD}_{90}$ (Figure 3D), as seen with constant pacing (Figure 2I). Thus, for all future simulations, we used a constant pacing interval that can more easily be standardized in a high-throughput drug-screening process.

\section{Effect of Conformational State Specificity and Binding/Unbinding Kinetics on Human Atrial Cardiomyocyte ERP at Normal and Fast Pacing Rates in CAF Conditions}

The desired effect of $\mathrm{I}_{\mathrm{Kur}}$ inhibitors is prolongation of atrial ERP (Amos et al., 1996; Christ et al., 2008; Sanchez et al., 2012; Loose et al., 2014; Ford et al., 2016), particularly during fast pacing rates typifying AF. Thus, we assessed the effects of binding/unbinding kinetics on the ERP for O (Figures 4A,B) and O \& I (Figures 4C,D) blockers. Simulations reveal a similar biphasic relationship between ERP and drug-binding kinetics at 1 - and $3-\mathrm{Hz}$ pacing for both types of inhibitors, which mirror the drugs' effects on APD (Figure 2).

At $1-\mathrm{Hz}$ pacing, $\mathrm{I}_{\mathrm{Kur}}$ inhibitors cause minimal ERP prolongation at slow drug-binding rates $\left(\leq 0.3 \mathrm{~s}^{-1}\right.$ for $\mathrm{O}$ blockers and $\leq 1 \mathrm{~s}^{-1}$ for $\mathrm{O}$ \& I blockers) and fast drug-binding rates $\left(100 \mathrm{~s}^{-1}\right)$. Although substantial ERP changes are predicted at intermediate drug-binding rates $\left(1-30 \mathrm{~s}^{-1}\right.$ for $\mathrm{O}$ blockers and $3-30 \mathrm{~s}^{-1}$ for $\mathrm{O} \&$ I blockers), ERP prolongation remains $\sim 62$ ms lower than the ERP in nSR given no block of $\mathrm{I}_{\mathrm{Kur}}$ for both inhibitors.

At $3-\mathrm{Hz}$ pacing, however, $\mathrm{I}_{\mathrm{Kur}}$ inhibitors appear to be more effective at extending ERP than APD, which is a favorable drug property as previously demonstrated for Class I antiarrhythmic drugs which cause clinically relevant postrepolarization refractoriness. For all drug-binding kinetics, ERP prolongation is at least equivalent to that caused by a constant $50 \%$ reduction in $\mathrm{G}_{\mathrm{Kur}}$ (Figures $4 \mathrm{~B}, \mathrm{D}$ ). Notably, for intermediate drug-binding kinetics (3-30 $\mathrm{s}^{-1}$ for O inhibitors and 10-30 $\mathrm{s}^{-1}$ for $\mathrm{O} \& \mathrm{I}$ inhibitors), drug-induced ERP prolongation extends above the ERP in nSR in drug-free conditions, and the fastest drug-binding kinetics prolong the ERP to a point that closely 

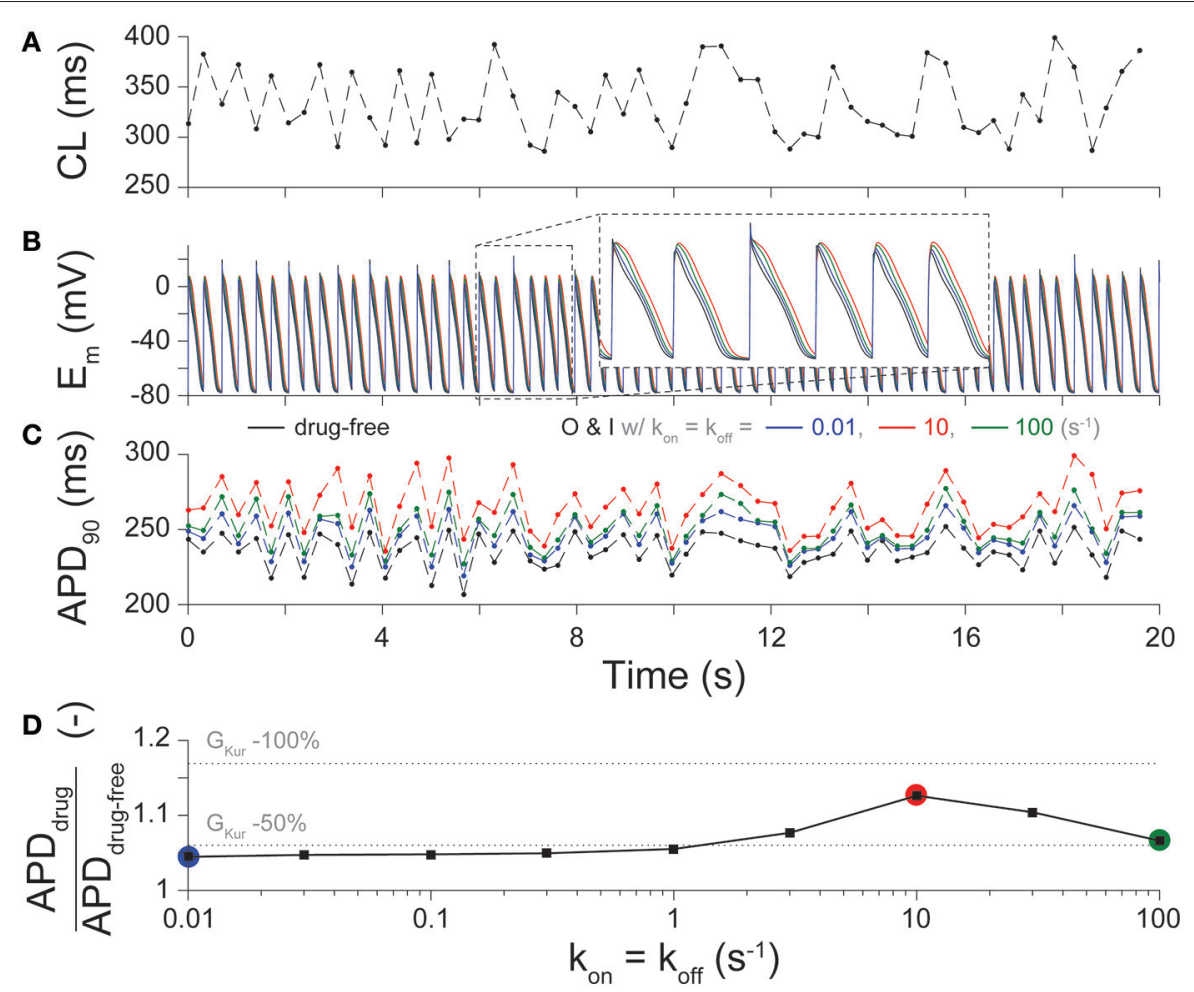

FIGURE 3 | Effect of drug-binding kinetics on APD during irregular pacing. (A) Beat-to-beat changes in CL during a 20-s irregular pacing protocol and the resultant time-course of (B) $E_{m}$, and (C) APD 90 are shown in $\mathrm{CAF}$ cardiomyocytes in drug-free conditions (black), and for $\mathrm{O}$ \& I blockers with slow ( $0.01 \mathrm{~s}^{-1}$, blue), intermediate $\left(10 \mathrm{~s}^{-1}\right.$, red), and fast $\left(100 \mathrm{~s}^{-1}\right.$, green) drug-binding kinetics, given $\mathrm{k}_{\mathrm{on}}=\mathrm{k}_{\mathrm{off}}$. (D) summarizes the percent prolongation (mean APDgo after application of drug divided by mean APDgo in drug-free conditions during the simulation) for nine different rates of binding kinetics between 0.01 and $100 \mathrm{~s}^{-1}$ using half-logarithmic increments,

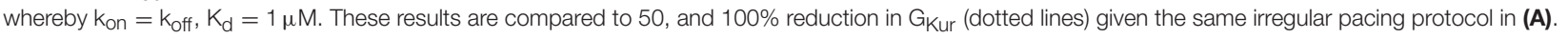

resembles that in $\mathrm{nSR}$ in drug-free conditions. These drugs showing substantial ERP prolongation at $3-\mathrm{Hz}$ pacing in $\mathrm{cAF}$ (with APD at slow pacing rates being well below that in nSR, see Figure 2) might represent suitable compounds for AF-selective therapy.

\section{Effects of Drug Binding/Unbinding Kinetics with Variable $\mathrm{K}_{\mathrm{d}}$ on APD, ERP, and $\mathrm{Ca}^{2+}$ Handling}

Figures 2, 3, 4 show the results from drug scenarios where the on- and off-rate of drug binding are equal to one another $\left(\mathrm{k}_{\mathrm{on}}=\right.$ $\mathrm{k}_{\mathrm{off}}, \mathrm{K}_{\mathrm{d}}=1 \mu \mathrm{M}$ ), but even closely related $\mathrm{I}_{\mathrm{Kur}}$ inhibitors can have dissimilar $K_{d}$ values (Lagrutta et al., 2006). Thus, we simulated all permutations of the nine different rates of drug binding $(0.01$ to $100 \mathrm{~s}^{-1}$ ), yielding 81 different combinations of $\mathrm{k}_{\mathrm{on}}$ and $\mathrm{k}_{\mathrm{off}}$ for the $\mathrm{O} \&$ I state inhibitors (assuming equal affinities for open and inactivated states) at $1-$ and $3-\mathrm{Hz}$ pacing. We assessed the effects of these drugs (at their $\mathrm{IC}_{50}$ concentration) on APD, ERP, $\mathrm{CaT}_{\mathrm{amp}}$, and diastolic $\left[\mathrm{Ca}^{2+}\right]_{\mathrm{i}}$. Figure 5 shows the output of the simulations for an $\mathrm{O} \& \mathrm{I}$ inhibitor (modeled as in Figure 2F, black) in the form of a heatmap, where the diagonals of the squares from the bottom left to the top right corner correspond to drug scenarios where $\mathrm{k}_{\mathrm{on}}=\mathrm{k}_{\mathrm{off}}\left(\mathrm{K}_{\mathrm{d}}=1 \mu \mathrm{M}\right)$. Except for the drugs with the largest $K_{d}$ values $\left(k_{o f f}>>k_{o n}\right)$, when $k_{o n}$ is held constant, APD, ERP, and $\mathrm{Ca}^{2+}$ handling are not very sensitive to changes in $\mathrm{k}_{\mathrm{off}}$. Thus, the effects of $\mathrm{I}_{\text {Kur }}$ inhibitors on atrial electrophysiology and $\mathrm{Ca}^{2+}$ handling are largely driven by $\mathrm{k}_{\mathrm{on}}$ rates as compared to $\mathrm{k}_{\mathrm{off}}$ rates.

In cAF conditions, ideal $\mathrm{I}_{\mathrm{Kur}}$ inhibitors exhibiting AFselectivity will prolong atrial refractoriness (ERP prolongation at $3-\mathrm{Hz}$ pacing), have limited toxicity (minimal to no APD prolongation at $1-\mathrm{Hz}$ pacing), and have a positive inotropic effect (an increase in $\mathrm{CaT}_{\mathrm{amp}}$ at $1-\mathrm{Hz}$ pacing). $\mathrm{O} \& \mathrm{I}$ inhibitors with a large $\mathrm{K}_{\mathrm{d}}$ do not display any of the desired favorable drug properties including prolongation of ERP at 3-Hz pacing (Figure 5B) or increase in $\mathrm{CaT}_{\mathrm{amp}}$ (Figures 5C,D), as their effects on APD, ERP, and $\mathrm{Ca}^{2+}$ handling are minimal, resembling drug-free conditions. Intermediate $k_{\text {on }}$ rates $\left(3-30 \mathrm{~s}^{-1}\right.$ for 1 $\mathrm{Hz}$ pacing and $10-30 \mathrm{~s}^{-1}$ for $3-\mathrm{Hz}$ pacing) cause the most significant increase in all the outputs displayed in Figure 5. For example, drugs with a $\mathrm{k}_{\text {on }}$ rate equal to $10 \mathrm{~s}^{-1}$ cause the greatest ERP prolongation at $3-\mathrm{Hz}$ pacing (Figure 5B) and increase in $\mathrm{CaT}_{\mathrm{amp}}$ and diastolic $\left[\mathrm{Ca}^{2+}\right]_{\mathrm{i}}$ (Figures $5 \mathrm{C}, \mathrm{E}$ ). Note, there is also significant APD prolongation at $1-\mathrm{Hz}$ pacing when $\mathrm{k}_{\mathrm{on}}$ is in the intermediate drug-binding range (Figure 5A), but none of the 81 permutations of the simulated open and inactivated state inhibitor cause the APD to get close to the APD in nSR at $1-\mathrm{Hz}$ 

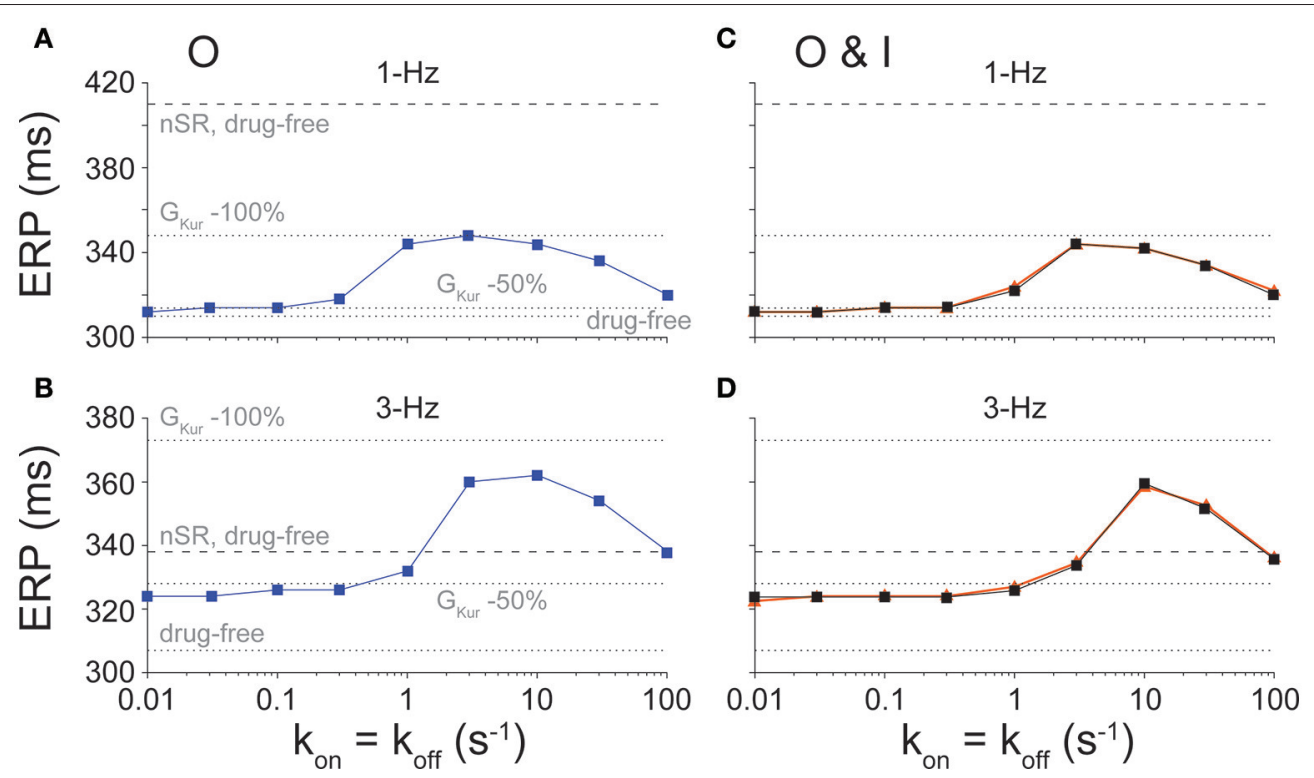

FIGURE 4 | Effect of state-dependence and kinetics of drug binding on ERP. ERP was determined for open $(\mathbf{A}, 1-\mathrm{Hz}$ and $\mathbf{B}, 3-\mathrm{Hz}$ pacing rate) and open and inactivated (C, $1-\mathrm{Hz}$ and $\mathbf{D}, 3-\mathrm{Hz}$ pacing rate) state blockers given nine different rates of binding kinetics between 0.01 and $100 \mathrm{~s}^{-1}$ using half-logarithmic increments, whereby $k_{\text {off }}=k_{o n}, K_{d}=1 \mu \mathrm{M}$. For $O$ \& I blockers, we either allowed or prevented transitions between drug-bound states (orange vs. black traces in $\mathbf{C}, \mathbf{D}$ ).

Simulations were also run in $\mathrm{nSR}$ and CAF drug-free conditions, and in CAF given a 50 and 100\% reduction in $\mathrm{G}_{\text {Kur. }}$.

pacing $(320 \mathrm{~ms})$. Thus, the APD prolongation seen in Figure 5A does not necessarily disqualify any of these theoretical drug candidates for AF therapy. Likewise, at $3-\mathrm{Hz}$ pacing, the increase in $\mathrm{CaT}_{\mathrm{amp}}$ and diastolic $\left[\mathrm{Ca}^{2+}\right]_{\mathrm{i}}$ mirrors the prolongation in APD and ERP at 3-Hz pacing (Figures 5D,F). While an excessive increase in diastolic $\left[\mathrm{Ca}^{2+}\right]_{\mathrm{i}}$ might be deleterious, we find it to remain well below the predicted value in the nSR human atrial cardiomyocyte model ( $360 \mathrm{nM})$.

In our previous study in nSR (Ellinwood et al., 2017), we found that $\mathrm{O} \& \mathrm{I}$ inhibitors with the fastest drug-binding kinetics (30-100 $\mathrm{s}^{-1}$ ) cause ERP prolongation at $3-\mathrm{Hz}$ pacing and no APD prolongation at $1-\mathrm{Hz}$ pacing. These same inhibitors display favorable fast pacing-rate selectivity in atrial cardiomyocytes from cAF according to our simulations shown in Figures 5A,B. However, if we are not as concerned with APD prolongation in $\mathrm{CAF}$ conditions at $1-\mathrm{Hz}$ pacing, then drugs with a $\mathrm{k}_{\text {on }}$ rate in the intermediate drug-binding range $\left(3-30 \mathrm{~s}^{-1}\right)$ would also be efficacious and perhaps more efficacious since they cause a positive inotropic effect at $1-\mathrm{Hz}$ pacing (Figures 5C,E).

\section{Effect of Relative State-Specific Drug Binding}

Because many $\mathrm{I}_{\mathrm{Kur}}$ inhibitors bind to multiple states of $\mathrm{K}_{\mathrm{V}} 1.5$ with variable affinity (Bouchard and Fedida, 1995; Lagrutta et al., 2006; Ford et al., 2016), we allowed $k_{\text {on }}$ for the open state $\left(\mathrm{k}_{\mathrm{on}, \mathrm{O}}\right), \mathrm{k}_{\mathrm{off}}$ for the open state $\left(\mathrm{k}_{\mathrm{off}, \mathrm{O}}\right), \mathrm{k}_{\mathrm{on}}$ for the inactivated state $\left(\mathrm{k}_{\mathrm{on}, \mathrm{I}}\right)$, and $\mathrm{k}_{\mathrm{off}}$ for the inactivated state $\left(\mathrm{k}_{\mathrm{off}, \mathrm{I}}\right)$ to have any of the three binding rates $\left(0.01,3\right.$, and $\left.100 \mathrm{~s}^{-1}\right)$, and varied them independently to yield 81 different drug combinations. We studied the effects of these $\mathrm{I}_{\text {Kur }}$ blockers in cAF conditions using a [drug] equal to their $\mathrm{IC}_{50}$ value at $1-\mathrm{Hz}$ pacing for $\mathrm{APD}$ and $3-\mathrm{Hz}$ pacing for ERP. Then, we compared the outputs of APD and ERP to no block, 50, and $100 \%$ reduction in $\mathrm{G}_{\mathrm{Kur}}$ in cAF conditions (Figure 6, dotted lines), along with no block in nSR conditions (Figure 6, dashed lines).

Figures 6A,B display the relationship between APD (at $1-\mathrm{Hz}$ pacing) and $\mathrm{K}_{\mathrm{O}} / \mathrm{K}_{\mathrm{I}}$. Data points in Figure $6 \mathrm{~A}$ are separated by IC $_{50}$ cutoffs of $0.1 \mu \mathrm{M}, 10 \mu \mathrm{M}$, and $1 \mathrm{mM}$, and show that when $\mathrm{K}_{\mathrm{O}} / \mathrm{K}_{\mathrm{I}}<1$, we almost always obtain maximal AP prolongation (this also corresponds to larger $\mathrm{IC}_{50}$ values). In Figure 6B, we separated the points according to the drug's $\mathrm{k}_{\mathrm{off}, \mathrm{O}}$ rate $(0.01,3$, or $100 \mathrm{~s}^{-1}$ ), which revealed that when $\mathrm{K}_{\mathrm{O}} / \mathrm{K}_{\mathrm{I}}>1$, we only obtain significant AP prolongation when $\mathrm{k}_{\mathrm{off}, \mathrm{O}}$ is equal to $3 \mathrm{~s}^{-1}$ (i.e., the intermediate drug-binding rate). These results in the cAFremodeled atrial cardiomyocyte correspond well with the results from our previous study of $\mathrm{I}_{\mathrm{Kur}}$ inhibitors in nSR (Ellinwood et al., 2017). Nevertheless, none of the 81 simulated O \& I inhibitors in Figure 6 prolong the AP beyond the APD found in $\mathrm{nSR}$ at $1-\mathrm{Hz}$ pacing.

Figures 6C,D present the relationship between APD at 1$\mathrm{Hz}$ pacing and ERP at $3-\mathrm{Hz}$ pacing for the $\mathrm{O} \& \mathrm{I}$ inhibitors with a variable $\mathrm{K}_{\mathrm{O}} / \mathrm{K}_{\mathrm{I}}$ ratio. In Figure $6 \mathrm{C}$, light gray symbols correspond to $\mathrm{K}_{\mathrm{O}} / \mathrm{K}_{\mathrm{I}} \leq 1$, and dark symbols correspond to $\mathrm{K}_{\mathrm{O}} / \mathrm{K}_{\mathrm{I}}>1$ ). The $\mathrm{O} \& \mathrm{I}$ blockers displaying favorable pacing-rate selectivity, i.e., producing ERP prolongation at $3-\mathrm{Hz}$ pacing while having moderate effect on APD (and ERP) at 1-Hz pacing, are the ones with $\mathrm{K}_{\mathrm{O}} / \mathrm{K}_{\mathrm{I}}>1$, except if $\mathrm{k}_{\mathrm{off}, \mathrm{O}}$ equals $3 \mathrm{~s}^{-1}$. However, as none of the 81 simulated $\mathrm{O} \& \mathrm{I}$ inhibitors in Figure 6 prolong the APD beyond that found in $\mathrm{nSR}$ at $1-\mathrm{Hz}$ pacing, one could argue that none of the drugs is expected to cause harmful AP prolongation when AF is terminated. To try and enrich our metric, in Figure 6D we also categorize the drugs according to 

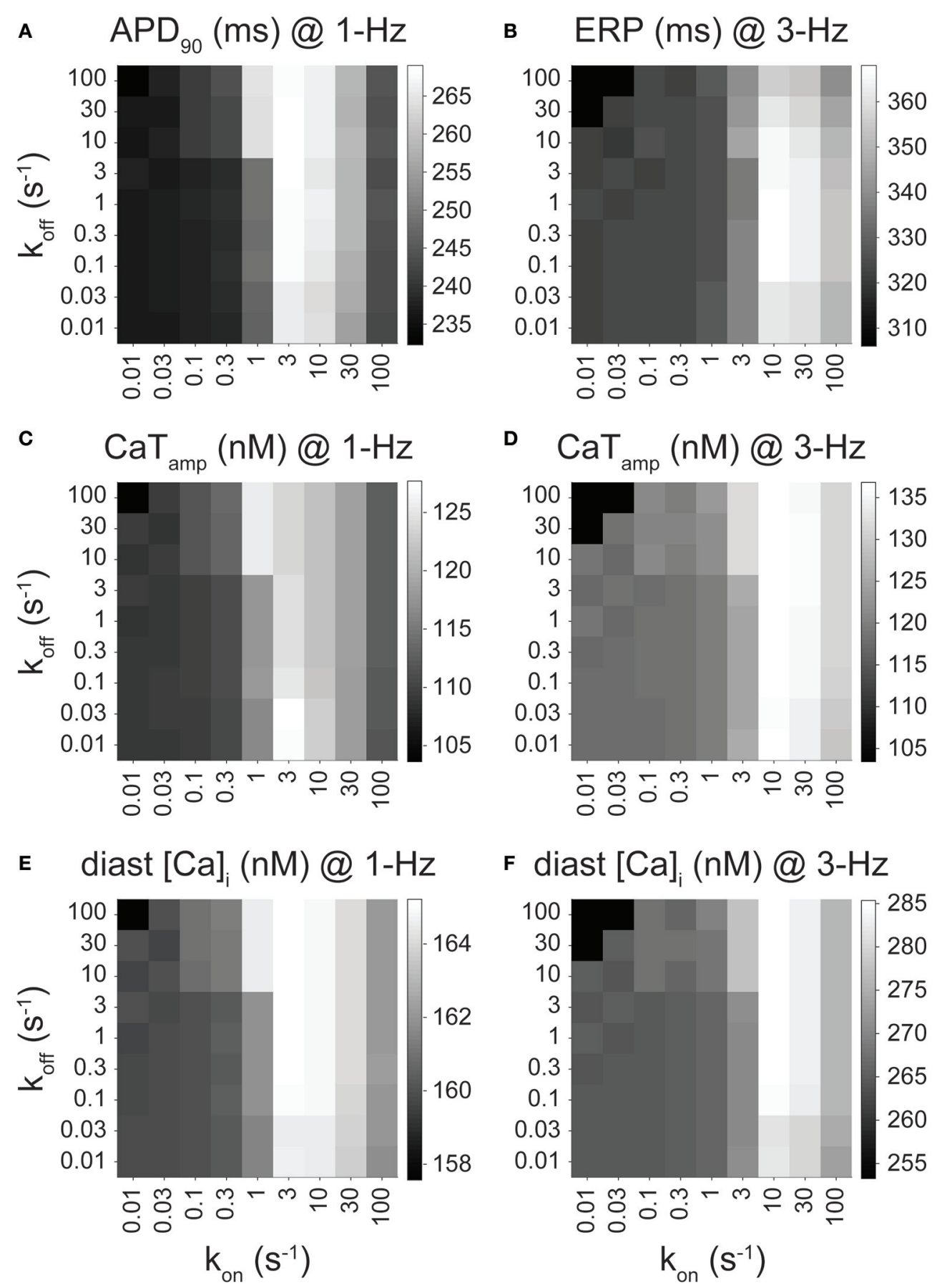

FIGURE 5 | Effect of drug-binding kinetics on APD90, ERP, CaTamp, and diastolic [Ca $\left.{ }^{2+}\right]_{i}$ for an open and inactivated state blocker. (A) APD90 (at 1 Hz), (B) ERP (at $3 \mathrm{~Hz}$ ), (C,D) $\mathrm{CaT}_{\mathrm{amp}}$ (at 1 and $3 \mathrm{~Hz}$ ), and $\mathbf{( E , F )}$ diastolic $\left[\mathrm{Ca}^{2+}\right]_{\mathrm{i}}$ (at 1 and $3 \mathrm{~Hz}$ ) are plotted for open and inactivated state blockers with varying binding kinetics, which were simulated via permutations of nine different drug-binding rates of (from 0.01 to $100 \mathrm{~s}^{-1}$ ) while keeping $\mathrm{k}_{\mathrm{on}, \mathrm{O}}=\mathrm{k}_{\mathrm{on}, \mathrm{I}}$ and $\mathrm{k}_{\mathrm{off}, \mathrm{O}}=\mathrm{k}_{\mathrm{off}, \mathrm{I}}$. CaT $\mathrm{Tmp}_{\text {is }} 103.6$, 109.4 , and $120.4 \mathrm{nM}$ at $1 \mathrm{~Hz}$, and $103.4,120.4$, and $135.9 \mathrm{nM}$ at $3 \mathrm{~Hz}$ for drug-free, 50 and $100 \%$ lKur block, respectively. Diastolic [Ca ${ }^{2+}$ ] is $157.6,160.0$, and $165.2 \mathrm{nM}$ at $1 \mathrm{~Hz}$, and 253.3, 266.9, and $286.9 \mathrm{nM}$ at $3 \mathrm{~Hz}$ for drug-free, 50 and $100 \%$ IKur block, respectively.

percent increase in $\mathrm{CaT}_{\mathrm{amp}}$. The best-performing drugs will cause ERP prolongation at $3-\mathrm{Hz}$ pacing in CAF (above nSR), and have a positive inotropic effect (Figure 6D, black). Corresponding with the results showcased in Figure 5, drugs with intermediate binding rates (e.g., $\mathrm{k}_{\text {off, } \mathrm{O}}=3 \mathrm{~s}^{-1}$ ) may thus be favorable given their stronger inotropic effect. 

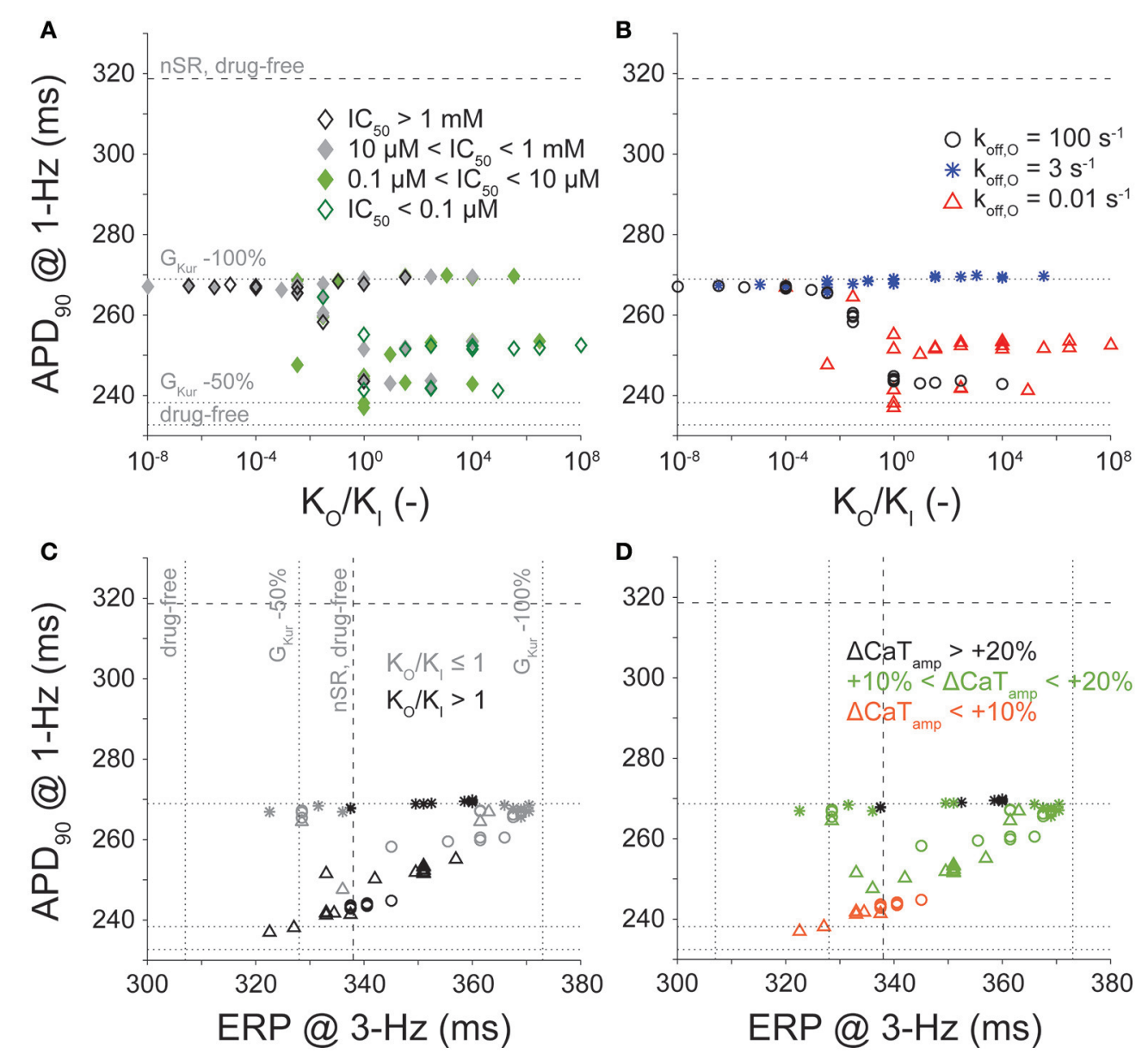

FIGURE 6 | Effect of conformational state affinity and drug-binding kinetics of an open and inactivated state blocker on APD90, ERP, and Ca ${ }^{2+}$ handling. Open and inactivated state $\mathrm{I}_{\mathrm{Kur}}$ blockers with varying affinities to the open and inactivated states were simulated via permutations of three different rates of binding kinetics $(0.01$, 3, and $100 \mathrm{~s}^{-1}$ ). Simulations were equilibrated for 300 beats at $1-\mathrm{Hz}$ pacing or 900 beats at 3- $\mathrm{Hz}$ pacing using a [drug] equal to the IC 50 value. (A,B) report APD90 values (at $1 \mathrm{~Hz}$ ) plotted as a function of the ratio of the open to the inactivated state affinity $\left(\mathrm{K}_{\mathrm{O}} / \mathrm{K}_{\mathrm{I}}\right)$ used in each simulation. (C,D) report $\mathrm{APD}$, $($ at $1 \mathrm{~Hz})$ and $\mathrm{ERP}$ values (at $3 \mathrm{~Hz}$ ). Color code in $\mathbf{( A )}$ is for $\mathrm{IC}_{50}$ levels. Symbols in $\mathbf{( B , C , D )}$ indicate various $\mathrm{K}_{\mathrm{off}, \mathrm{O}}$. Shades in $\mathbf{( C )}$ reflect either higher affinity to the open or the inactivated

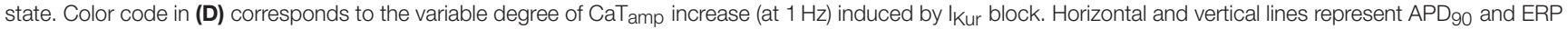
values obtained in CAF in drug-free conditions, and 50 and $100 \%$ reduction in $\mathrm{G}_{\text {Kur }}$ (dotted lines), and in nSR in drug-free conditions (dashed lines).

\section{DISCUSSION}

In this study, we sought to determine if $\mathrm{I}_{\mathrm{Kur}}$ is a suitable antiAF target despite it being downregulated in CAF patients, and, if so, what are the kinetic and state-dependent binding properties that maximize anti-AF efficacy and limit potential cardiotoxicity. Building off our previous study in nSR conditions (Ellinwood et al., 2017), we implemented an in silico assessment of $I_{K u r}$ inhibitors in cAF atrial cardiomyocyte models, and identified metrics for delineating ideal $\mathrm{K}_{\mathrm{V}} 1.5$ blockers against AF. Our results point to $\mathrm{I}_{\mathrm{Kur}}$ inhibition as a valid strategy to prolong atrial refractoriness also generating a positive inotropic effect in $\mathrm{CAF}$ conditions. Although increasing force generation may not be a useful therapeutic goal at the high atrial rates seen during AF, it can be important to counteract atrial hypocontractility after cardioversion of AF to nSR. Interestingly, our simulations suggest that electrophysiological properties in CAF cardiomyocytes, such as shorter AP and more depolarized plateau potential, both might act to increase efficacy and dampen cardiotoxicity of potential $\mathrm{K}_{\mathrm{V}}$ 1.5-targeting drugs as compared to nSR (Ellinwood et al., 2017; Figure 7).

\section{IKur Role in APD and ERP Regulation Is Preserved Despite Its Downregulation in cAF}

Figure S7 shows the differences in the time courses of $E_{m}$, $I_{K u r}$, and closed, open, and inactivated state occupancies of $\mathrm{K}_{\mathrm{V}} 1.5$ in $\mathrm{cAF}$ and $\mathrm{nSR}$ during the AP. Despite the reduced peak current, the channel stays open later in CAF (at both 1- and 3$\mathrm{Hz}$ pacing) because of the more depolarized AP plateau. Thus, the consequences of $\mathrm{I}_{\mathrm{Kur}}$ inhibition, including the extent of AP 


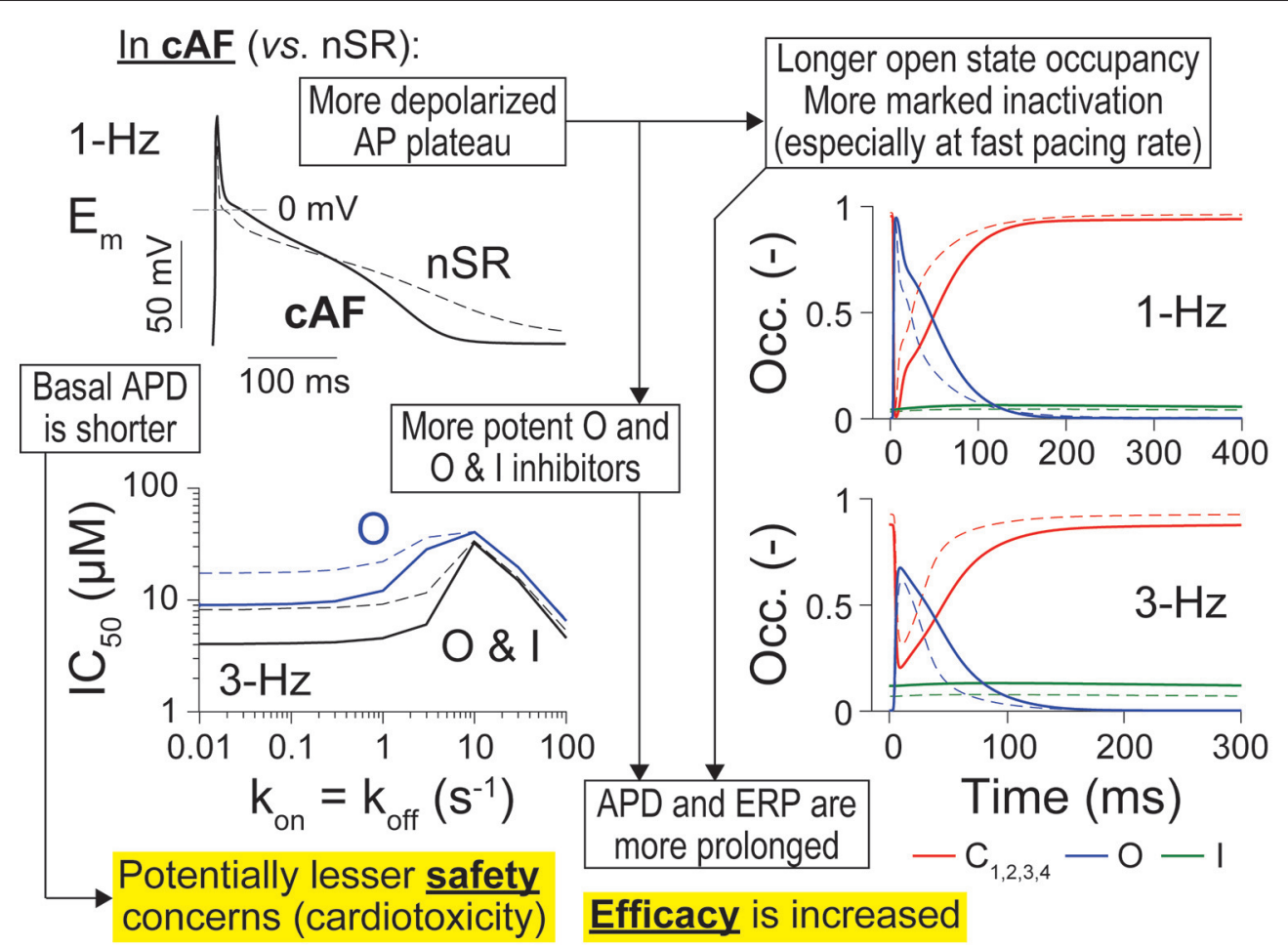

FIGURE 7 | Summary of main findings. Atrial cardiomyocytes in CAF (solid lines) vs. nSR (dotted lines) have different AP trajectories, including a shorter APD and more depolarized plateau (top left). The latter causes longer open state occupancy (right, blue solid vs. dashed lines) and stronger inactivation of the channel in cAF conditions (especially at fast pacing rates, right, green solid vs. dashed lines). IKur inhibitors appear also more potent in cAF vs. nSR (bottom left). These factors render APD and ERP more sensitive to inhibition by $O$ and $O \& I$ inhibitors of $K_{V} 1.5$, thus increasing efficacy of these drugs in cAF vs. nSR. Because basal APD is shorter in $\mathrm{CAF}$, there are potentially less safety concerns due to drug-induced AP prolongation and subsequent afterdepolarization-driven proarrhythmia.

and ERP prolongation, depend not only on $\mathrm{I}_{\text {Kur }}$ magnitude (i.e., maximal conductance), but also on other fluxes affected by AFinduced remodeling, which affect $\mathrm{E}_{\mathrm{m}}$ and thus $\mathrm{E}_{\mathrm{m}}$-dependent properties of $\mathrm{I}_{\mathrm{Kur}}$ (Figure 7). For example, our group and others have hypothesized that the extent of AP and ERP prolongation due to $\mathrm{I}_{\text {Kur }}$ blockade depends on the AF-induced remodeling of other $\mathrm{K}^{+}$currents (Lagrutta et al., 2006; Morotti et al., 2016a; Aguilar et al., 2017; Colman et al., 2017), and relative strengths of $\mathrm{I}_{\mathrm{CaL}}$ and $\mathrm{I}_{\mathrm{Kur}}$ (Wettwer et al., 2004; Grandi and Maleckar, 2016). Our sensitivity analysis (Figure 1C and Figures S1-S6) revealed that $\mathrm{APD}_{90}$ and ERP are more sensitive to changes in $\mathrm{G}_{\mathrm{Kur}}$ at fast vs. slow pacing rates. Aguilar et al. recently determined that the relative contribution of $\mathrm{I}_{\mathrm{Kur}}$ to AP repolarization increases at higher frequencies because of reduced activation of the rapid delayed-rectifier current $\mathrm{I}_{\mathrm{Kr}}$ (Aguilar et al., 2017). Our results concur with these findings, as our sensitivity analysis shows that $\mathrm{APD}_{90}$ and ERP are less sensitive to changes in $\mathrm{G}_{\mathrm{Kr}}$ at $3-\mathrm{Hz}$ pacing as compared to $1-\mathrm{Hz}$ pacing in nSR conditions (Figures S2, S3). Most importantly, we also found that $\mathrm{G}_{\mathrm{Kur}}$ impacted the duration of AP repolarization and refractoriness more in cAF vs. nSR (even though this parameter was halved in the cAF model) at $3-\mathrm{Hz}$, but not at $1-\mathrm{Hz}$ pacing (i.e., fast pacing-rate selectivity). This is a favorable drug property to avoid harmful AP prolongation (which is also limited by the reduced basal APD) if AF is terminated. Similar to Aguilar et al. (2017), our results suggest that the APD- (and ERP)-prolonging effect of $\mathrm{I}_{\text {Kur }}$ block is not affected by $\mathrm{I}_{\mathrm{Kur}}$ downregulation.

\section{Enhanced Efficacy and Safety of IKur Inhibitors in CAF vs. nSR}

We focused here on $\mathrm{O}$ and $\mathrm{O} \&$ I blockers because we have previously shown that these inhibitors display fast pacing-rate selectivity in nSR (Ellinwood et al., 2017). This choice was also supported by the increased occupancy of open and inactivated states in CAF conditions (Figure 7). In our previous report in nSR (Ellinwood et al., 2017), we found that when $\mathrm{k}_{\mathrm{on}}=\mathrm{k}_{\mathrm{off}}$ (i) slow drug-binding kinetics caused minimal APD changes and modest ERP prolongation; (ii) intermediate drug-binding kinetics led to substantial AP and ERP prolongation; and (iii) fast drug-binding kinetics failed to produce substantial AP or ERP prolongation at normal pacing rate, but increased the ERP at $3-\mathrm{Hz}$ pacing. While in CAF the overall biphasic relationship between APD/ERP and drug-binding kinetics was maintained (see Figures 2-4), notably, at $1-\mathrm{Hz}$ pacing rate, even the maximal AP prolongation induced by $\mathrm{I}_{\text {Kur }}$ inhibition in $\mathrm{CAF}$ is not sufficient to reach the APD observed in nSR in drug-free conditions. This might indicate that there are less safety concerns for $\mathrm{K}_{\mathrm{V}} 1.5$ block in cAF patients. At $3-\mathrm{Hz}$ pacing, ERP prolongation is at least equivalent to that caused by a constant $50 \%$ reduction in $\mathrm{G}_{\mathrm{Kur}}$, and, for intermediate and fast drug-binding kinetics, the ERP 
is equal to or greater than the one obtained in nSR in drugfree conditions. These observations suggest that $\mathrm{O}$ and $\mathrm{O} \& \mathrm{I}$ inhibitors have a broader range of efficacy in cAF vs. nSR. We assessed whether closed state inhibitors, which displayed reverserate dependence in terms of potency (Ellinwood et al., 2017), may also be effective and safe anti-AF agents in $\mathrm{CAF}$ conditions (Figure S8). We found that these blockers prolong ERP at $3-\mathrm{Hz}$ pacing (Figure S8G) while minimally prolonging the cAF AP at $1-\mathrm{Hz}$ pacing at the fastest drug-binding kinetics $\left(\geq 30 \mathrm{~s}^{-1}\right.$, Figure S8B). However, they had a smaller maximal effect and kinetic range for prolonging the ERP at $3-\mathrm{Hz}$ pacing beyond $\mathrm{nSR}$ conditions as compared to $\mathrm{O}$ and $\mathrm{O} \& \mathrm{I}$ blockers.

We enriched our metric for quantifying anti-AF efficacy and safety of $\mathrm{I}_{\mathrm{Kur}}$ inhibitors by also accounting for changes in $\mathrm{Ca}^{2+}$-handling parameters, namely CaT $\mathrm{T}_{\mathrm{amp}}$ and diastolic $\left[\mathrm{Ca}^{2+}\right]_{\mathrm{i}}$ (Tsujimae et al., 2008; Cavero and Holzgrefe, 2014; Lancaster and Sobie, 2016; Li et al., 2017), which provided additional detail to refine the search for best-performing drugs. In identifying the ideal drug characteristics, we looked for inhibitors that prolong ERP (especially at fast pacing rates), limit APD prolongation at slow pacing-rates, and improve atrial inotropy, i.e., increase $\mathrm{CaT}_{\mathrm{amp}}$. Increasing force generation might be a useful outcome after cardioversion to nSR.

When $\mathrm{K}_{\mathrm{O}}=\mathrm{K}_{\mathrm{I}}$, the best-performing $\mathrm{O}$ \& I inhibitors were those with intermediate $k_{\text {on }}$ rates $\left(3-30 \mathrm{~s}^{-1}\right.$ ), because they prolonged ERP at $3-\mathrm{Hz}$ pacing and increased $\mathrm{CaT}_{\mathrm{amp}}$ and diastolic $\left[\mathrm{Ca}^{2+}\right]_{\mathrm{i}}$ at $1-\mathrm{Hz}$ pacing (Figure 5). These inhibitors also prolonged the AP at $1-\mathrm{Hz}$ pacing and increased $\mathrm{CaT}_{\mathrm{amp}}$ and diastolic $\left[\mathrm{Ca}^{2+}\right]_{i}$ at $3-\mathrm{Hz}$ pacing-thus potentially predisposing to harmful AP prolongation and $\mathrm{Ca}^{2+}$ overload. However, we note that such cardiotoxicity is unlikely considering the fact that the maximum increases of APD and $\mathrm{CaT}_{\mathrm{amp}}$ still remain far below the corresponding values obtained in nSR in drug-free conditions. In our previous study, we highlighted that the bestperforming drugs in nSR were the $\mathrm{O} \& \mathrm{I}$ inhibitors with the fastest drug-binding kinetics (Ellinwood et al., 2017). While these drugs are still efficacious at prolonging ERP at $3-\mathrm{Hz}$ pacing in $\mathrm{CAF}$, they have limited effect on $\mathrm{Ca}^{2+}$ handling.

When $\mathrm{K}_{\mathrm{I}}$ and $\mathrm{K}_{\mathrm{O}}$ were varied, the relationships between APD at $1-\mathrm{Hz}$ pacing and affinity ratio $\left(\mathrm{K}_{\mathrm{O}} / \mathrm{K}_{\mathrm{I}}\right)$ are similar to those in nSR (Figures 6A,B; Ellinwood et al., 2017), except none of the 81 simulated O \& I inhibitors prolonged the AP beyond the duration found in nSR in drug-free condition. Likewise, the relationship between APD at $1-\mathrm{Hz}$ pacing and ERP at 3-Hz pacing is similar to nSR (Figures 6C,D; Ellinwood et al., 2017), but none of the drugs exhibit obvious toxicity. The same $\mathrm{O} \& \mathrm{I}$ inhibitors simulated in cAF conditions were more effective at prolonging ERP at $3-\mathrm{Hz}$ pacing rates as compared to nSR conditions. Thus, on average, the same inhibitors in Figure 6 exhibit less toxicity and greater efficacy in cAF vs. nSR.

In their simulation study, Aguilar et al. concluded that the ability of (simple pore) $\mathrm{I}_{\mathrm{Kur}}$ block to terminate simulated AF was greatly attenuated by remodeling, because the block-induced AP prolongation was insufficient to counteract the strong effects of cAF-induced remodeling (Aguilar et al., 2017). Notably, here we show that depending on the drug-binding kinetics, certain $\mathrm{I}_{\mathrm{Kur}}$ inhibitors can markedly counteract the effect of cAF-associated remodeling, and bring AP and ERP parameters close to nSR values, i.e., have a greater effect than simple pore blockers.

\section{Limitations and Future Directions}

We presented a theoretical study of the effects of $\mathrm{I}_{\text {Kur }}$ inhibitors in $\mathrm{CAF}$, and compared our results to our previous study in nSR atrial cardiomyocytes. We acknowledge several limitations to the described approach, which provide opportunities for further extensions. First, we only considered direct drug effects on $\mathrm{K}_{\mathrm{V}} 1.5$, and future analysis should consider multi-channel effects of $\mathrm{I}_{\mathrm{Kur}}$ inhibitors (Ford and Milnes, 2008; Li et al., 2017), as this realistically occurs in vivo in the clinical setting. We only considered cardiotoxicity at the atrial level, assuming that the absence of $I_{K u r}$ in ventricles prevents ventricular proarrhythmia. However, this might not be true for real $\mathrm{I}_{\mathrm{Kur}}$ blockers with off-target effects. Here, we simulated $\mathrm{I}_{\text {Kur }}$ block at the cellular level with no contribution of structural tissue remodeling and defined $\mathrm{I}_{\mathrm{Kur}}$ inhibitors' efficacy and toxicity by tracking only electrophysiological properties such as APD, ERP, $\mathrm{CaT}_{\text {amp }}$, and diastolic $\left[\mathrm{Ca}^{2+}\right]_{\mathrm{i}}$. While this is an important first step in defining metrics for AF-selectivity, other arrhythmia indices and integration of such simulations into tissue and organ level models would improve our ability to discern bestperforming drug characteristics of $\mathrm{I}_{\mathrm{Kur}}$ inhibitors against $\mathrm{AF}$. Since many antiarrhythmic drugs lose anti-AF efficacy with the progression of the arrhythmia, particularly in patients with atrial cardiomyopathy and comorbidities (Goette et al., 2016), $\mathrm{I}_{\mathrm{Kur}}$ block might be less efficient against AF in the structurally remodeled atrium. Further studies including 2- and 3-dimensional tissue simulations are needed to address this clinically relevant issue. In addition, machine-learning methods have begun to be implemented to analyze AP metrics after the application of a drug and classify the risk (e.g., torsadogenic risk) of the candidate drug (Lancaster and Sobie, 2016). Such methods can also highlight which ion channels contribute most to such risk. Furthermore, this study revealed that the efficacy and toxicity of $\mathrm{I}_{\mathrm{Kur}}$ inhibitors is modulated by the extent of atrial ionic remodeling, and likely by the relative expressions of many ion channels and transporters (Figures S1-S6). Thus, given the differences in AP properties and ion channel expression in patients with AF (Heijman et al., 2014), and differences in $\mathrm{I}_{\mathrm{Kur}}$ remodeling in the right vs. the left atria (Dobrev and Ravens, 2003; Caballero et al., 2010), we hypothesize that certain subpopulations of nSR and cAF patients may be more responsive to therapy with $\mathrm{I}_{\mathrm{Kur}}$ inhibitors, i.e., degree and heterogeneity of $\mathrm{I}_{\mathrm{Kur}}$ remodeling in atrial tissue might impact safety and antiAF efficacy of drugs. Future studies could identify which cell characteristics lead to more favorable responses to anti- $I_{K u r}$ therapy utilizing sensitivity analysis and variations of nSR and cAF models similar to the methods discussed in Figure 1 and in (Sobie, 2009; Lee et al., 2013; Cummins et al., 2014; Devenyi and Sobie, 2015; Morotti and Grandi, 2017). This information could be useful for a personalized (precision) medicine approach to AF treatment or helpful in suggesting potential combination therapies with $\mathrm{I}_{\mathrm{Kur}}$ inhibitors.

Finally, advancements in high-throughput screening methods (Obergrussberger et al., 2016; Picones et al., 2016; Molokanova 
et al., 2017) provide functional drug screening capabilities that can be coupled with in silico investigations such as the one described here to help identify actual candidate compounds for in vivo testing. Such technologies can potentially be implemented to simultaneously screen many $\mathrm{K}_{\mathrm{V}} 1.5$-selective compounds for the desired kinetics, state-dependence, and rate-dependence of $\mathrm{I}_{\text {Kur }}$ block. In addition, multi-parallel recordings from atrial-like cardiomyocytes from induced human pluripotent stem cells is also emerging as a preclinical model for evaluating drugs targeting atrial-specific ion channels, such as $\mathrm{K}_{\mathrm{V}} 1.5$ (Devalla et al., 2015), particularly in combination with APclamp experiments. These could be coupled with in silico studies such as this one for delineating the ideal properties of AF-selective drugs and gaining a more comprehensive understanding of the arrhythmic risk of candidate compounds.

\section{CONCLUSIONS}

In this study, efficacy and cardiotoxicity on cAF atrial cardiomyocytes of theoretical $\mathrm{I}_{\mathrm{Kur}}$ inhibitors were assessed in silico. We concluded that $\mathrm{I}_{\mathrm{Kur}}$ is a promising anti-AF target, even if strongly downregulated in cAF condition. We confirmed that steady-state $\mathrm{IC}_{50}$ values are insufficient to predict how candidate compounds will interact with a dynamically changing electrophysiological substrate, thus emphasizing the importance of accounting for kinetic and state-dependent drug-binding properties. This approach could aid experimental and screening

\section{REFERENCES}

Aguilar, M., Feng, J., Vigmond, E., Comtois, P., and Nattel, S. (2017). Rate-dependent role of $\mathrm{I}_{\mathrm{Kur}}$ in human atrial repolarization and atrial fibrillation maintenance. Biophys. J. 112, 1997-2010. doi: 10.1016/j.bpj.2017. 03.022

Amos, G. J., Wettwer, E., Metzger, F., Li, Q., Himmel, H. M., and Ravens, U. (1996). Differences between outward currents of human atrial, and subepicardial ventricular myocytes. J. Physiol. 491, 31-50. doi: 10.1113/jphysiol.1996.sp021194

Andrade, J., Khairy, P., Dobrev, D., and Nattel, S. (2014). The clinical profile and pathophysiology of atrial fibrillation: relationships among clinical features, epidemiology, and mechanisms. Circ. Res. 114, 1453-1468. doi: 10.1161/CIRCRESAHA.114.303211

Bers, D. M., and Grandi, E. (2011). Human atrial fibrillation: insights from computational electrophysiological models. Trends Cardiovasc. Med. 21, 145-150. doi: 10.1016/j.tcm.2012.04.004

Bosch, R. F., Zeng, X.,Grammer, J. B., Popovic, K., Mewis, C., and Kuhlkamp, V. (1999). Ionic mechanisms of electrical remodeling in human atrial fibrillation. Cardiovasc. Res. 44, 121-131. doi: 10.1016/S0008-6363(99)00178-9

Bouchard, R., and Fedida, D. (1995). Closed- and open-state binding of 4aminopyridine to the cloned human potassium channel Kv1.5. J. Pharmacol. Exp. Ther. 275, 864-876.

Brandt, M. C., Priebe, L., Bohle, T., Sudkamp, M., and Beuckelmann, D. J. (2000). The ultrarapid and the transient outward $\mathrm{K}^{+}$current in human atrial fibrillation. Their possible role in postoperative atrial fibrillation. J. Mol. Cell Cardiol. 32, 1885-1896. doi: 10.1006/jmcc.2000.1221

Caballero, R., de la Fuente M. G., Gomez, R., Barana, A., Amoros, I., DolzGaiton, P., et al. (2010). In humans, chronic atrial fibrillation decreases the transient outward current and ultrarapid component of the delayed rectifier current differentially on each atria and increases the slow component of efforts to identify the complex net impact of $\mathrm{I}_{\mathrm{Kur}}$ inhibition in different AF-remodeling conditions during the pre-clinical drug development process.

\section{AUTHOR CONTRIBUTIONS}

Designed simulation experiments: NE, SM, EG. Performed modeling and simulations: NE, SM. Wrote the manuscript: NE, DD, SM, EG.

\section{ACKNOWLEDGMENTS}

The authors would like to thank Dr. Lucía Romero Pérez, Polytechnic University of Valencia, for her critical reading of this manuscript. This work was supported by the National Institute of Health grant R01-HL131517 (to EG and DD), the American Heart Association grant 15SDG24910015 (EG), the Heart Rhythm Society post-doctoral fellowship 16OA9HRS (SM), the Bill Bertken Sudden Death Prevention Fund, and the National Center for Advancing Translational Sciences, National Institutes of Health, through grant number UL1 TR001860 and linked award TL1 TR001861 (NE).

\section{SUPPLEMENTARY MATERIAL}

The Supplementary Material for this article can be found online at: https://www.frontiersin.org/articles/10.3389/fphar. 2017.00799/full\#supplementary-material the delayed rectifier current in both. J. Am. Coll. Cardiol. 55, 2346-2354. doi: 10.1016/j.jacc.2010.02.028

Cavero, I., and Holzgrefe, H. (2014). Comprehensive in vitro proarrhythmia assay, a novel in vitro/in silico paradigm to detect ventricular proarrhythmic liability: a visionary $21^{\text {st }}$ century initiative. Expert Opin. Drug Saf. 13, 745-758. doi: 10.1517/14740338.2014.915311

Christ, T., Wettwer, E., Voigt, N., Hala, O., Radicke, S., Matschke, K., et al (2008). Pathology-specific effects of the $\mathrm{I}_{\mathrm{Kur}} / \mathrm{Ito} / \mathrm{I}_{\mathrm{K}, \mathrm{ACh}}$ blocker AVE0118 on ion channels in human chronic atrial fibrillation. Br. J. Pharmacol. 154, 1619-1630. doi: 10.1038/bjp.2008.209

Christophersen, I. E., Olesen, M. S., Liang, B., Andersen, M. N., Larsen, A. P., Nielsen J. B., et al. (2013). Genetic variation in KCNA5: impact on the atrialspecific potassium current $\mathrm{I}_{\mathrm{Kur}}$ in patients with lone atrial fibrillation. Eur. Heart J. 34, 1517-1525. doi: 10.1093/eurheartj/ehs442

Colman, M. A., Ni, H., Liang, B., Schmitt, N., and Zhang, H. (2017). In silico assessment of genetic variation in KCNA5 reveals multiple mechanisms of human atrial arrhythmogenesis. PLoS Comput. Biol. 13:e1005587. doi: 10.1371/journal.pcbi.1005587

Cummins, M. A., Dalal, P. J., Bugana, M., Severi, S., and Sobie, E. A. (2014). Comprehensive analyses of ventricular myocyte models identify targets exhibiting favorable rate dependence. PLoS Comput. Biol. 10:e1003543. doi: 10.1371/journal.pcbi.1003543

Devalla, H. D., Schwach, V., Ford, J. W., Milnes, J. T., El-Haou, S., Jackson C., et al. (2015). Atrial-like cardiomyocytes from human pluripotent stem cells are a robust preclinical model for assessing atrial-selective pharmacology. EMBO Mol. Med 7, 394-410. doi: 10.15252/emmm. 201404757

Devenyi, R. A., and Sobie, E. A. (2015). There and back again: iterating between population-based modeling and experiments reveals surprising regulation of calcium transients in rat cardiac myocytes. J. Mol. Cell Cardiol. 96, 38-48. doi: $10.1016 /$ j.yjmcc.2015.07.016 
Dobrev, D., and Ravens, U. (2003). Remodeling of cardiomyocyte ion channels in human atrial fibrillation. Basic Res. Cardiol. 98, 137-148. doi: 10.1007/s00395-003-0409-8

Ehrlich, J. R., Biliczki, P., Hohnloser, S. H., and Nattel, S. (2008). Atrial-selective approaches for the treatment of atrial fibrillation. J. Am. Coll. Cardiol. 51, 787-792. doi: 10.1016/j.jacc.2007.08.067

Ellinwood, N., Dobrev, D., Morotti, S., and Grandi, E. (2017). Revealing kinetics and state-dependent binding properties of $\mathrm{I}_{\mathrm{Kur}}$-targeting drugs that maximize atrial fibrillation selectivity Chaos 27:093918. doi: 10.1063/1.5000226

Ford, J. W., and Milnes, J. T., (2008). New drugs targeting the cardiac ultrarapid delayed-rectifier current $\mathrm{I}_{\mathrm{Kur}}$ : rationale, pharmacology and evidence for potential therapeutic value. J. Cardiovasc. Pharmacol. 52, 105-120. doi: 10.1097/FJC.0b013e3181719b0c

Ford, J., Milnes, J., El Haou, S., Wettwer, E., Loose, S., Matschke, K., et al. (2016). The positive frequency-dependent electrophysiological effects of the

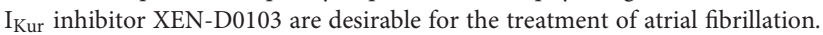
Heart Rhythm 13, 555-564. doi: 10.1016/j.hrthm.2015.10.003

Ford, J., Milnes, J., Wettwer, E., Christ, T., Rogers, M., Sutton, K., et al. (2013). Human electrophysiological and pharmacological properties of XEN-D0101: a novel atrial-selective Kv1.5/I Kur inhibitor. J. Cardiovasc. Pharmacol 61, 408-415. doi: 10.1097/FJC.0b013e31828780eb

Goette, A., Kalman, J. M., Aguinaga, L., Akar, J., Cabrera, J. A., Chen S. A., et al. (2016). EHRA/HRS/APHRS/SOLAECE expert consensus on atrial cardiomyopathies: definition, characterization, and clinical implication. Europace 18, 1455-1490. doi: 10.1093/europace/euw161

Grammer, J. B., Bosch, R. F., Kuhlkamp, V., and Seipel, L. (2000). Molecular remodeling of $\mathrm{Kv} 4.3$ potassium channels in human atrial fibrillation. J. Cardiovasc. Electrophysiol. 11, 626-633. doi: 10.1111/j.1540-8167.2000.tb00024.x

Grandi, E., and Maleckar, M. M. (2016). Anti-arrhythmic strategies for atrial fibrillation: the role of computational modeling in discovery, development, and optimization. Pharmacol. Ther. 168, 126-142. doi: 10.1016/j.pharmthera.2016.09.012

Grandi, E., Pandit, S. V., Voigt, N., Workman, A. J., Dobrev, D., Jalife, J., et al. (2011). Human atrial action potential and $\mathrm{Ca}^{2+}$ model: sinus rhythm and chronic atrial fibrillation. Circ. Res. 109, 1055-1066. doi: 10.1161/CIRCRESAHA.111.253955

Grandi, E., Workman, A. J., and Pandit, S. V. (2012). Altered excitationcontraction coupling in human chronic atrial fibrillation. J. Atr. Fibrillation 4:495. doi: 10.4022/jafib.495

Heijman, J., Voigt, N., Nattel, S., and Dobrev, D. (2014). Cellular and molecular electrophysiology of atrial fibrillation initiation, maintenance, and progression. Circ. Res. 114, 1483-1499. doi: 10.1161/CIRCRESAHA.114.302226

Lagrutta, A., Wang, J., Fermini, B., and Salata, J. J. (2006). Novel, potent inhibitors of human $\mathrm{Kv} 1.5 \mathrm{~K}^{+}$channels and ultrarapidly activating delayed rectifier potassium current. J. Pharmacol. Exp. Ther. 317, 1054-1063. doi: 10.1124/jpet.106.101162

Lancaster, M. C., and Sobie, E. A. (2016). Improved prediction of drug-induced torsades de pointes through simulations of dynamics and machine learning algorithms. Clin. Pharmacol. Ther. 100, 371-379. doi: 10.1002/cpt.367

Lee, W., Mann, S. A., Windley,M. J., Imtiaz, M. S., Vandenberg, J. I., and Hill, A. P. (2016). In silico assessment of kinetics and state dependent binding properties of drugs causing acquired LQTS. Prog. Biophys. Mol. Biol. 120, 89-99. doi: 10.1016/j.pbiomolbio.2015.12.005

Lee, Y. S., Liu, O. Z., Hwang, H. S., Knollmann, B. C. and Sobie, E. A. (2013). Parameter sensitivity analysis of stochastic models provides insights into cardiac calcium sparks. Biophys. J. 104, 1142-1150. doi: 10.1016/j.bpj.2012.12.055

Li, Z., Dutta, S., Sheng, J., Tran, P. N., Wu, W., Chang, K. et al. (2017). Improving the In silico assessment of proarrhythmia risk by combining hERG (human ether-a-go-go-related gene) channel-drug binding kinetics and multichannel pharmacology. Circ. Arrhythm. Electrophysiol. 10:e004628. doi: 10.1161/CIRCEP.116.004628

Loose, S., Mueller, J., Wettwer, E., Knaut, M., Ford, J., Milnes, J., et al. (2014). Effects of $\mathrm{I}_{\text {Kur }}$ blocker MK-0448 on human right atrial action potentials from patients in sinus rhythm and in permanent atrial fibrillation. Front. Pharmacol. 5:26. doi: 10.3389/fphar.2014.00026
Molokanova, E., Mercola, M., and Savchenko, A. (2017). Bringing new dimensions to drug discovery screening: impact of cellular stimulation technologies. Drug Discov. Today 22, 1045-1055. doi: 10.1016/j.drudis.2017. 01.015

Morotti, S., and Grandi, E. (2017). Logistic regression analysis of populations of electrophysiological models to assess proarrythmic risk. MethodsX 4, 25-34. doi: 10.1016/j.mex.2016.12.002

Morotti, S., Koivumäki, J. T., Maleckar, M. M., Chiamvimonvat, N., and Grandi, E. (2016a). Small-conductance $\mathrm{Ca}^{2+}$-activated $\mathrm{K}^{+}$current in atrial fibrillation: both friend and foe. Biophys. J. 110:274a. doi: 10.1016/j.bpj.2015.11.1487

Morotti, S., McCulloch, A. D., Bers, D. M., Edwards, A. G., and Grandi, E. (2016b). Atrial-selective targeting of arrhythmogenic phase-3 early afterdepolarizations in human myocytes. J. Mol. Cell Cardiol. 96, 63-71. doi: 10.1016/j.yjmcc.2015.07.030

Morotti, S., Nieves-Cintron, M., Nystoriak, M. A., Navedo, M. F., and Grandi, E. (2017). Predominant contribution of L-type Cav1.2 channel stimulation to impaired intracellular calcium and cerebral artery vasoconstriction in diabetic hyperglycemia, Channels 11, 340-346. doi: 10.1080/19336950.2017.1293220

Nattel, S., and Dobrev, D. (2016). Electrophysiological and molecular mechanisms of paroxysmal atrial fibrillation. Nat. Rev. Cardiol. 13, 575-590. doi: $10.1038 /$ nrcardio.2016.118

Obergrussberger, A., Bruggemann, A., Goetze, T. A., Rapedius, M., Haarmann, C., Rinke, I., et al. (2016). Automated patch clamp meets high-throughput screening: 384 cells recorded in parallel on a planar patch clamp module. J. Lab. Autom. 21, 779-793. doi: 10.1177/2211068215623209

Olson, T. M., Alekseev, A. E., Liu, X. K., Park, S., Zingman, L.V., Bienengraeber, M., et al. (2006). Kv1.5 channelopathy due to KCNA5 loss-of-function mutation causes human atrial fibrillation. Hum. Mol. Genet. 15, 2185-2191. doi: $10.1093 / \mathrm{hmg} / \mathrm{ddl} 143$

Picones, A., Loza-Huerta, A., Segura-Chama, P., and Lara-Figueroa, C. O. (2016). Contribution of automated technologies to ion channel drug discovery. Adv. Protein Chem. Struct. Biol. 104, 357-378. doi: 10.1016/bs.apcsb.2016.01.002

Ravens, U., Poulet, C., Wettwer, E., and Knaut, M. (2013). Atrial selectivity of antiarrhythmic drugs J. Physiol. 591, 4087-4097. doi: 10.1113/jphysiol.2013.256115

Sanchez, C., Corrias, A., Bueno-Orovio, A., Davies, M., Swinton, J., Jacobson, I., et al. (2012). The $\mathrm{Na}^{+} / \mathrm{K}^{+}$pump is an important modulator of refractoriness and rotor dynamics in human atrial tissue. Am. J. Physiol. Heart Circ. Physiol. 302, H1146-H1159. doi: 10.1152/ajpheart.00668.2011

Schotten, U., de Haan, S., Verheule, S., Harks, E. G., Frechen, D. Bodewig, E., et al. (2007). Blockade of atrial-specific $\mathrm{K}^{+}$-currents increases atrial but not ventricular contractility by enhancing reverse mode $\mathrm{Na}^{+} / \mathrm{Ca}^{2+}$-exchange. Cardiovasc. Res. 73, 37-47. doi: 10.1016/j.cardiores.2006.11.024

Shinagawa, K., Mitamura, H., Takeshita, A., Sato, T., Kanki, H., Takatsuki, S., et al. (2000). Determination of refractory periods and conduction velocity during atrial fibrillation using atrial capture in dogs: direct assessment of the wavelength and its modulation by a sodium channel blocker, pilsicainide. J. Am. Coll. Cardiol. 35, 246-253. doi: 10.1016/S0735-1097(99)00488-X

Sobie, E. A. (2009). Parameter sensitivity analysis in electrophysiological models using multivariable regression. Biophys. J. 96, 1264-1274. doi: 10.1016/j.bpj.2008.10.056

Tsujimae, K., Murakami, S., and Kurachi, Y. (2008). In silico study on the effects of $\mathrm{I}_{\mathrm{Kur}}$ block kinetics on prolongation of human action potential after atrial fibrillation-induced electrical remodeling. Am. J. Physiol. Heart Circ. Physiol. 294, H793-H800. doi: 10.1152/ajpheart.01229.2007

Van Wagoner, D. R., and Nerbonne, J. M. (2000). Molecular basis of electrical remodeling in atrial fibrillation. J. Mol. Cell Cardiol. 32, 1101-1117. doi: 10.1006/jmcc.2000.1147

Van Wagoner, D. R., Piccini, J. P., Albert, C. M., ,Anderson, M. E., Benjamin, E. J., Brundel, B. et al. (2015). Progress toward the prevention and treatment of atrial fibrillation: a summary of the heart rhythm society research forum on the treatment and prevention of atrial fibrillation, Washington, DC, December 9-10, 2013. Heart Rhythm 12, e5-e29. doi: 10.1016/j.hrthm.2014.11.011

Van Wagoner, D. R., Pond, A. L., McCarthy, P. M., Trimmer, J. S., and Nerbonne, J. M. (1997). Outward $\mathrm{K}^{+}$current densities and $\mathrm{K}_{\mathrm{V}} 1.5$ expression are reduced in chronic human atrial fibrillation. Circ. Res. 80, 772-781. doi: 10.1161/01.RES.80.6.772 
Wang, D., Shryock, J. C., and Belardinelli, L. (1996). Cellular basis for the negative dromotropic effect of adenosine on rabbit single atrioventricular nodal cells. Circ. Res. 78, 697-706. doi: 10.1161/01.RES.78.4.697

Wettwer, E., Hala, O., Christ, T., Heubach, J. F., Dobrev, D., Knaut, M., et al. (2004). Role of $\mathrm{I}_{\text {Kur }}$ in controlling action potential shape and contractility in the human atrium: influence of chronic atrial fibrillation. Circulation 110, 2299-2306. doi: 10.1161/01.CIR.0000145155.60288.71

Workman, A. J., Kane, K. A., and Rankin, A. C. (2001). The contribution of ionic currents to changes in refractoriness of human atrial myocytes associated with chronic atrial fibrillation. Cardiovasc. Res. 52, 226-235. doi: 10.1016/S0008-6363(01)00380-7

Yue, L., Feng, J., Gaspo, R., Li, G. R., Wang, Z., and Nattel, S. (1997). Ionic remodeling underlying action potential changes in a canine model of atrial fibrillation. Circ. Res. 81, 512-525. doi: 10.1161/01.RES.81.4.512

Zhao, Q., Tang, Y., Okello, E., Wang, X., and Huang, C. (2009). Changes in atrial effective refractory period and $\mathrm{I}_{\mathrm{KACh}}$ after vagal stimulation plus rapid pacing in the pulmonary vein. Rev. Esp. Cardiol 62, 742-749. doi: 10.1016/S0300-8932(09)71687-2

Zhou, Q., Bett, G. C., and Rasmusson, R. L. (2012). Markov models of usedependence and reverse use-dependence during the mouse cardiac action potential. PLoS ONE 7:e42295. doi: 10.1371/journal.pone.0042295

Conflict of Interest Statement: The authors declare that the research was conducted in the absence of any commercial or financial relationships that could be construed as a potential conflict of interest.

Copyright (c) 2017 Ellinwood, Dobrev, Morotti and Grandi. This is an open-access article distributed under the terms of the Creative Commons Attribution License (CC $B Y)$. The use, distribution or reproduction in other forums is permitted, provided the original author(s) or licensor are credited and that the original publication in this journal is cited, in accordance with accepted academic practice. No use, distribution or reproduction is permitted which does not comply with these terms. 